\title{
Amplitude Sampled Reference-Based Space Vector Pulse Width Modulation for Control of Voltage Source Converters
}

\author{
Mohamed Khalid Ratib*, Ahmed Rashwan
}

Department of Electrical Engineering, Faculty of Energy Engineering, Aswan University, Aswan, Egypt

\begin{abstract}
Memory, speed, reliability, and efficiency are the main characteristics of concern in new contemporary control techniques of electric power converters. Space vector pulse width modulation (SVPWM) is a widespread digital compute-intensive control technique used in the control of power converters. This study aims to overcome the large number of calculations needed by the SVPWM algorithm, which limits its implementation in many advanced industrial applications. This paper presents a low-cost software implemented simplified SVPWM technique. The proposed strategy generates the inverter switching times in a straightforward manner with no need for complicated and time-consuming sector identification and look-up switching tables. A simulation study has been done using MATLAB/SIMULINK environment for the three-phase voltage source converter (VSC). The results in terms of total harmonic distortion (THD) in the converter line voltage are compared for the proposed technique, conventional SVPWM, and space pulse width modulation (SPWM). The execution time is reduced considerably with a slight increase in the value of THD and about 14.4 percent DC-link voltage utilization over the SPWM.
\end{abstract}

Index Terms: Offset voltage, sinusoidal pulse width modulation, space vector pulse width modulation and voltage source converter.

\footnotetext{
${ }^{*}$ Corresponding author.

E-mail: mohammedkhalid@energy.aswu.edu.eg
}

http://dx.doi.org/10.38028/esr.2021.02.0005

Received July 26, 2021. Revised July 01, 2021.

Accepted July 11, 2021. Available online July 23, 2021.

This is an open access article under a Creative Commons Attribution-NonCommercial 4.0 International License.

C) 2021 ESI SB RAS and authors. All rights reserved.

\section{INTRODUCTION}

Electrical energy conversion is a common term nowadays [1]. Electrical energy conversion devices are ordinarily named converters. Electrical power converters have become extensively used with various types and ratings ranging from low voltage to high voltage in many industrial applications [2], [3]. Optimum voltage vectors can be exerted to the power grid or attached loads by various electrical power converters such as two-level voltage source converter (2L-VSC), matrix converter, AC / AC voltage converter, and multilevel inverters. In the midst of all these, the three-phase 2L-VSC is an interesting topology used in almost all drive applications because it covers both medium and high-power range applications.

Besides, these converters can be controlled by many control techniques, which all aim to improve the converter efficiency by reducing the switching power loss and the ratio of total harmonic distortion (THD) in the converter output voltage [4], [5]. Among these control approaches, pulse width modulation (PWM) is the most common control method used in industrial applications these days. PWM has many different techniques [6], [7]. Sinusoidal and space vector pulse width modulations (SPWM, SVPWM) are the most well-known techniques among the PWM methodologies. The PWM technique is reliable when the current or voltage required for driving a typical load are to be obtained. Due to the lower harmonic current and the maximum output voltage conducted to load, the PWM procedure is generally used for AC drives [8], [9]. The vital objective in all PWM methods is to generate the necessary amplitude and frequency of the fundamental frequency component along with a reduction in the THD value [10], [11].

Carrier-based sinusoidal PWM generates gating signals for switches by comparing a modulating signal with a triangular carrier signal [4]. These modulating signals are usually three-phase sinusoidal reference waveforms. SPWM has a relatively high current harmonic content and THD 
Table 1: Switching states and space vectors of the three-phase 2L-VSC.

\begin{tabular}{|c|c|c|c|c|c|c|c|c|c|}
\hline \multicolumn{3}{|c|}{ Switching state } & \multicolumn{3}{|c|}{ Switches } & \multirow[t]{2}{*}{$V_{n}$} & \multirow[t]{2}{*}{ States } & \multirow[t]{2}{*}{$V_{0}$} & \multirow[t]{2}{*}{$\boldsymbol{\alpha}_{0}$} \\
\hline$S_{A}$ & $S_{B}$ & $S_{C}$ & & & & & & & \\
\hline 1 & 0 & 0 & $S_{1}$ & $S_{4}$ & $S_{6}$ & $V_{1}=\frac{2}{3} V_{d c}$ & +1 & $\frac{2}{3} V_{d c}$ & 0 \\
\hline 1 & 1 & 0 & $S_{1}$ & $S_{3}$ & $S_{6}$ & $V_{2}=\frac{1}{3} V_{d c}+j \frac{\sqrt{3}}{2} V_{d c}$ & +2 & $\frac{2}{3} V_{d c}$ & $\frac{\pi}{3}$ \\
\hline 0 & 1 & 0 & $S_{2}$ & $S_{3}$ & $S_{6}$ & $V_{3}=-\frac{1}{3} V_{d c}+j \frac{\sqrt{3}}{2} V_{d c}$ & +3 & $\frac{2}{3} V_{d c}$ & $\frac{2 \pi}{3}$ \\
\hline 0 & 1 & 1 & $S_{2}$ & $S_{3}$ & $S_{5}$ & $V_{4}=-\frac{2}{3} V_{d c}$ & -1 & $-\frac{2}{3} V_{d c}$ & 0 \\
\hline 0 & 0 & 1 & $S_{2}$ & $S_{4}$ & $S_{5}$ & $V_{5}=-\frac{1}{3} V_{d c}-j \frac{\sqrt{3}}{2} V_{d c}$ & -2 & $-\frac{2}{3} V_{d c}$ & $\frac{\pi}{3}$ \\
\hline 1 & 0 & 1 & $S_{1}$ & $S_{4}$ & $S_{5}$ & $V_{6}=\frac{1}{3} V_{d c}-j \frac{\sqrt{3}}{2} V_{d c}$ & -3 & $-\frac{2}{3} V_{d c}$ & $\frac{2 \pi}{3}$ \\
\hline 0 & 0 & 0 & $S_{2}$ & $S_{4}$ & $S_{6}$ & $V_{0}=0$ & $0_{0}$ & 0 & - \\
\hline 1 & 1 & 1 & $S_{1}$ & $S_{3}$ & $S_{5}$ & $V_{7}=0$ & $0_{7}$ & 0 & - \\
\hline
\end{tabular}

value compared with more sophisticated PWM methods; and, SVPWM is one of these methods [12]. SVPWM relies on the space vector distribution of a typical converter, and a specific reference voltage vector is synthesized by two active voltage vectors and one zero vector. The time values related to these three vectors are calculated and distributed according to some preferred time sequencing diagrams [13], [14]. Considering these time values for six sectors, a modified modulating signal is obtained and compared with a triangular carrier signal to get the switching pulses for all switches in a converter.

SVPWM is a superior digital PWM technique with many admirable advantages. It is a sophisticated, computeintensive, and possibly the best of all PWM methods for variable frequency drive applications [15]. However, a large number of calculations and incredible computational effort are essentially the main drawbacks of space vector modulation (SVM) [16]. A new simplified approach based on the principle of adding an offset voltage to the original sinusoidal phase reference signal to obtain a re-shaped signal to be used as a modulating signal has been developed in recent years [17]. This approach can be used with all PWM procedures.

Following this procedure, SVM could be interestingly simplified and the modulating wave of SVPWM be generated directly from the three sinusoidal phase reference voltages [18]. Without any computational effort or timeconsuming calculations, SVM is introduced here in this work with MATLAB simulation to support and reinforce the use of VSCs controlled with this method for AC drives and industrial applications.
The main contribution of this paper is a software-coded and implemented method for SVPWM simplification. This work also presents a comparative analysis of software implemented techniques (SPWM, conventional SVPWM, and the simplified SVPWM). Furthermore, the application of the offset voltage procedure to simplify SVM in a programmable code implementation is an intrinsic aim in this paper. Section II of this paper briefly considers VSCs and a basic power circuit for the three-phase 2L-VSC. Section III briefly presents and explains the pulse duration modulation techniques. Section IV contains the parameters and results of MATLAB simulation and related discussion. Section $\mathrm{V}$ concludes the results expected from the proposed method, and, finally, the references used are listed at the end of this paper.

\section{POWER CIRCUIT FOR THE THREE-PHASE 2L-VSC}

A VSC generates AC voltage from a DC voltage, and it can transfer power in either direction. The DC voltage always has one polarity, and the power reversal occurs through the current polarity reversal. With a voltage source converter, output voltage magnitude and frequency can be controlled independently. VSCs have many different configurations and topologies for single and three-phase systems [19], [20]. The two-level neutral-point-clamped converter, modular multilevel converter (MMC), variant MMC, and alternatearm converter (AAC) are all types of voltage source converters. There are also hybrid VSC systems, which aim to achieve low losses and high harmonic performance of MMC with a more compact design and greater controllability, but these concepts are still under research [21], [22]. 


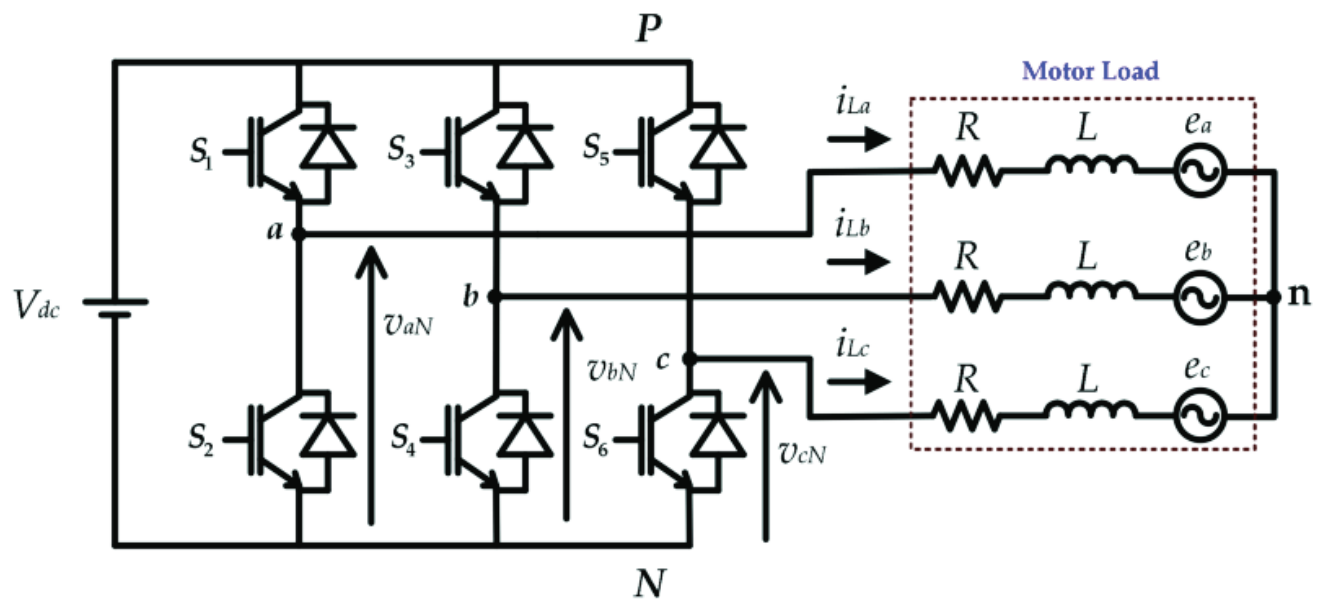

Fig. 1. 2L-VSC with an RL load [23]

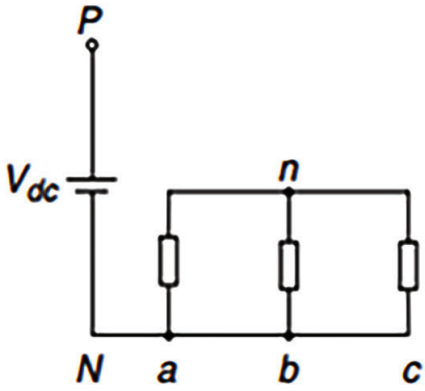

$V_{0}(0,0,0)$

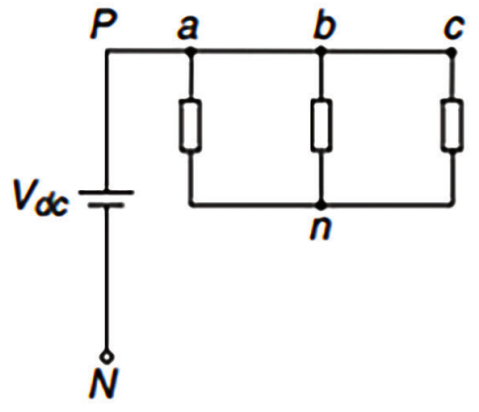

$V_{7}(1,1,1)$

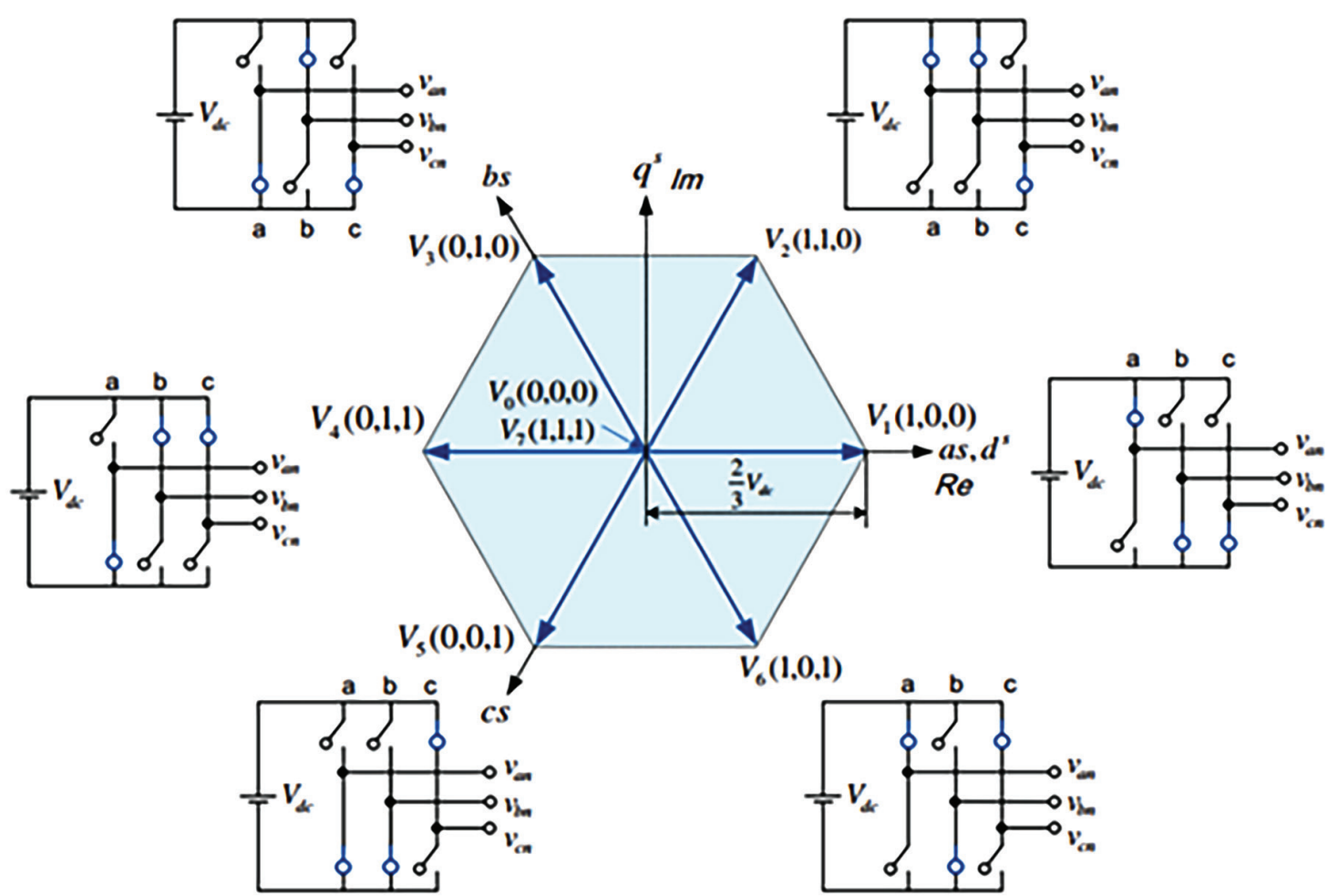

Fig. 2. Output voltage vectors of the three-phase inverter with associated switching states in the complex $\alpha-\beta$ plane. 
This paper focuses on 2L-VSC since it is the simplest one for implementation in most of the electrical power conversion systems found today. The electric circuit studied here consists of a constant DC voltage source and a three-phase 2L-VSC connected with an RL load.

\section{Power Circuit of $2 L-V S C$}

The three-phase $2 \mathrm{~L}-\mathrm{VSC}$ has six power switches $\left(s_{1}\right.$ $-s_{6}$ ) in its power circuit, as shown in Fig.1 [23]. These switches should operate in a complementary mode to avoid the DC source short-circuit. The switching state of each of the power switches $S_{x}$ with $x=1 \ldots 6$, can be declared with switching signals $S_{a}, S_{b}$, and $S_{c}$ corresponding to three phases as follows:

$$
\begin{aligned}
& S_{a}=\left\{\begin{array}{l}
1 \text { when } S_{1} O N \text { and } S_{4} O F F, \\
0 \text { when } S_{1} O F F \text { and } S_{4} O N,
\end{array}\right. \\
& S_{b}=\left\{\begin{array}{l}
1 \text { when } S_{2} O N \text { and } S_{5} O F F, \\
0 \text { when } S_{2} O F F \text { and } S_{5} O N,
\end{array}\right. \\
& S_{c}=\left\{\begin{array}{l}
1 \text { when } S_{3} O N \text { and } S_{6} O F F, \\
0 \text { when } S_{3} O F F \text { and } S_{6} O N .
\end{array}\right.
\end{aligned}
$$

The inverter output voltages can be defined with these switching signals as:

$$
\begin{aligned}
& v_{a N}=S_{a} V_{d c}, \\
& v_{b N}=S_{b} V_{d c}, \\
& v_{c N}=S_{c} V_{d c},
\end{aligned}
$$

where $V_{d c}$ is the $\mathrm{DC}$ voltage connected to the inverter.

Considering the unit vector $\mathbf{a}=e^{j 2 \pi / 3}=-\frac{1}{2}+\frac{j \sqrt{3}}{2}$ which represents the $120^{\circ}$ phase displacement between the phases, the output voltage vector can be defined as:

$$
V_{0}=\frac{2}{3}\left(v_{a N}+\mathbf{a} v_{b N}+\mathbf{a}^{2} v_{c N}\right)=V_{\max } \cdot e^{j \alpha},
$$

Where $v_{a N}, v_{b N}$, and $v_{c N}$ are the phase-to-neutral $(N)$ voltages of the inverter. Various voltage vectors can be produced when the available switching states are applied to the inverter power circuit due to different configurations of the three-phase load connection to the DC source. The three-phase inverter has eight possible switching states that result in eight inverter output voltage vectors. These voltage vectors are listed in Table. 1, and shown in Fig. 2 , as six active vectors distributed in space and two zero vectors located at the origin of the complex $\alpha-\beta$ plane. All the six voltage vectors have the same magnitude of $\frac{2}{3} V_{d c}$ but are displaced from each other by 60 degrees in space. As shown in Fig.2, the zero vectors $V_{0}$ and $V_{7}$ are equal to zero and located at the origin in the complex $\alpha-\beta$ plane.

\section{Pulse-duration modulation techniques for inverters}

Pulse-duration modulation (PDM) or pulse-width modulation (PWM), is a method of controlling the average
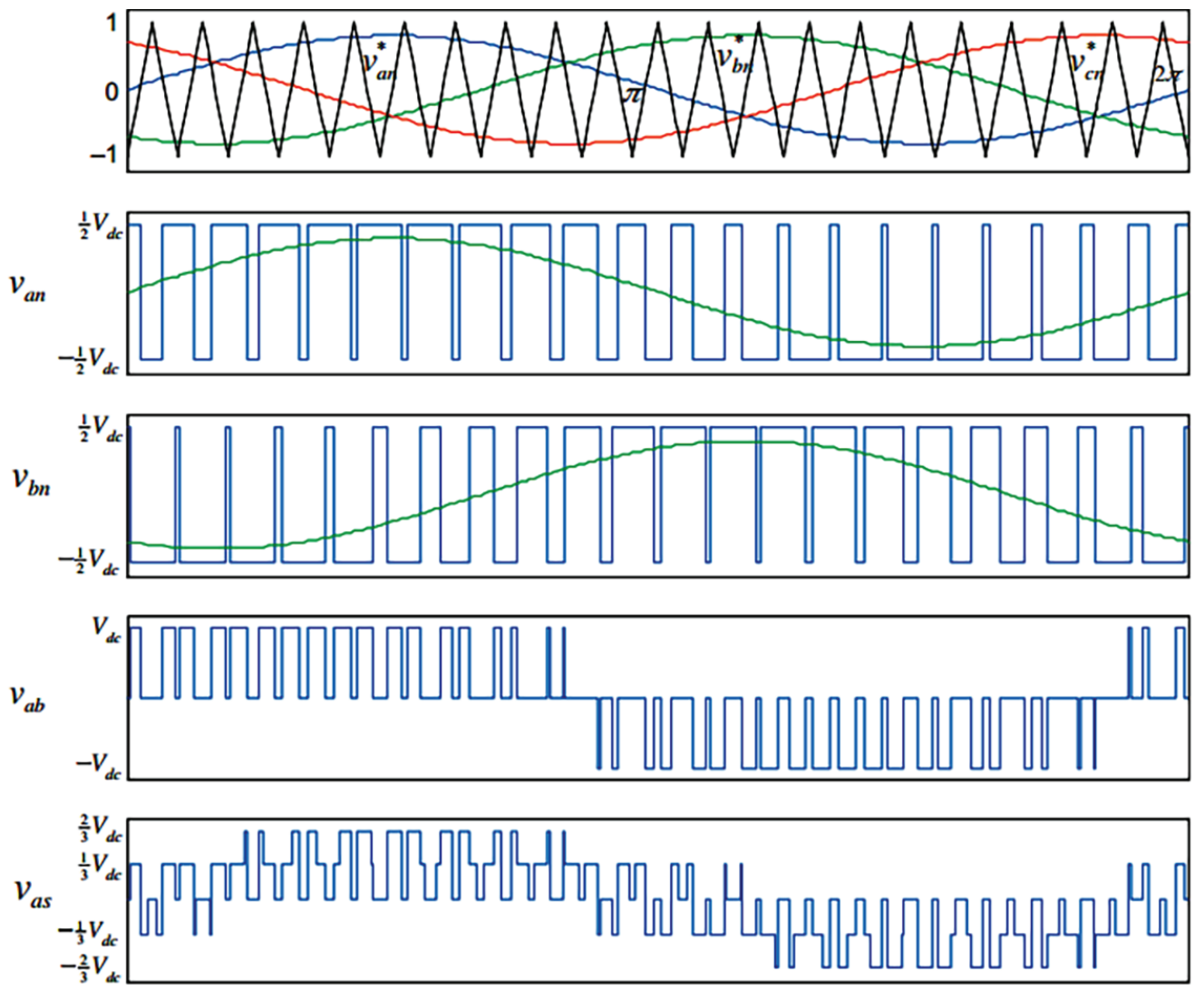

Fig. 3. SPWM technique for the three-phase two-level inverter [18] 
power delivered by an electrical signal by effectively chopping it up into discrete parts. The average value of voltage (and current) fed to the load is controlled by quickly turning the switch on and off. The longer the switch is on compared to the off periods, the higher the total power supplied to the load. PWM is particularly suited for inertial loads such as motors, which are not easily affected by this discrete switching because they have inertia to react slowly [24]. The PWM switching frequency has to be high enough not to affect the load, and the waveform perceived by load should be as smooth as possible. The main advantage of PWM is that power loss in the switching devices is very low. When a switch is off, there is practically no current, and when it is on and power is transferred to load, there is almost no voltage drop across the switch. Power loss, i.e., the product of voltage and current, is thus in both cases close to zero. PWM also works well with digital controls, which, because of their on/off nature, can easily set the needed duty cycle.

PDM can be used effectively in the control of VSCs, and it usually has various techniques. These control techniques are classified and depicted in [18]. This paper is dedicated to the study and analysis of output waveforms and performance of $2 \mathrm{~L}-\mathrm{VSC}$ with two of these main techniques plus a modified version of one of them:

a. Carrier-based SPWM;

b. SVPWM or SVM (Continuous - Symmetrical PWM);

c. SVPWM with a reduced computational burden.

It is worth noting that the switching frequency of highpower converters is constricted to some low values of 350 $\mathrm{Hz}$ to $1 \mathrm{kHz}$ to reduce/minimize the switching losses. This results in low values of $m_{f}$ that can be defined as the ratio of switching frequency to fundamental component frequency, where $f_{s w}=f_{c r}$ for 2L-VSC, which, in turn, makes the inverter output voltage rich in harmonics. For this reason, $m_{f}$ should be a multiple of three to achieve symmetry, and the output voltage should be synchronized with its fundamental component to eliminate subharmonics.

\section{The SPWM technique for three-phase $2 L$-VSC}

The basis of the sinusoidal PWM technique for the three-phase 2L-VSC is shown in Fig. 3, where $v_{a n}^{*}, v_{b n}^{*}$, and $v_{c n}^{*}$ are the three-phase modulating signals and $v_{c r}$ is the triangular carrier signal.

The amplitude and frequency of the fundamental frequency component of the inverter output voltage can be controlled independently by the amplitude modulation index and frequency of the modulating waves, respectively.

The amplitude and frequency modulation indexes are defined by:

$$
m_{a}=\frac{V_{m}}{V_{c r}}, \quad m_{f}=\frac{f_{c r}}{f_{m}},
$$

where $V_{m}, f_{m}$, and $V_{c r}, f_{c r}$ are the modulating and carrier maximum voltage and frequency, respectively.

For linear modulation, the modulation index should be in a range of $0 \leq m_{a} \leq 1$ for the inverter output voltage to be directly proportional to the reference voltage. When $m_{a} \geq 1, V_{m} \geq V_{c r}$ and the case called overmodulation occurs, where the inverter output voltage is no longer linearly proportional to the reference voltage. The maximum output line-to-line voltage that could be obtained with the SPWM technique used is about $0.612 V_{d c}$.

4. The SVPWM technique for three-phase $2 L$-VSC with the conventional algorithm

PWM has many different techniques with various bases; Unlike the SPWM where the three-phase reference voltages are modulated individually, the SVPWM uses a different approach of transforming the rotating threephase reference voltages to two voltages in the stationary reference frame, where they are expressed as a space vector $V_{a b c}$ in the complex $\alpha-\beta$ plane.

The SVPWM method is an advanced computeintensive PWM technique, and it is one of the best techniques for real-time modulation, which is why it is widespread in the digital control of VSCs and variablefrequency drive applications [25],[26].

The three-phase 2L-VSC has six active vectors ( $V_{1}$ to $V_{6}$ ) that divide the plane into six sectors in space (each one spans 60 degrees in space) and two zero vectors $\left(V_{0}, V_{7}\right)$. With SVM technique, the reference voltage $V_{\text {ref }}$ is synthesized in various sectors by two adjacent non-zero vectors and one zero vector to produce a voltage that has the same fundamental volt-second average as the given reference voltage vector $V_{r e f}$ over the modulation period $T_{s}$.

If the voltage reference vector is located in sector (1), as shown in Fig. 4, the inverter cannot generate this reference voltage vector directly because the inverter has no output voltage vector that has the same magnitude and phase angle as this reference voltage vector. Instead, and according to Table 2, this reference vector can be synthesized from the inverter output voltage vectors based on the average Volt-Second Principle using two adjacent active vectors $V_{1}$ and $V_{2}$, and zero vector $V_{0 / 7}$ as follows: firstly, the voltage vector $V_{1}$ is applied with a duty time $T_{a}$, which results in an output voltage of magnitude $V_{1} \cdot\left(T_{a} /\right.$ $T_{b}$ ) and the same direction as $V_{1}$; secondly, another vector $V_{2}$ is applied to time $T_{b}$ to meet the magnitude and phase of the reference voltage vector $V_{r e f}$. An output voltage, the same as the reference voltage, can be obtained using these two steps over the modulation period $T_{s}$. Lastly, if the sum of $T_{a}$ and $T_{b}$ is less than the modulation period $T_{s}$, one zero vector $V_{0 / 7}$ is applied for the rest of the time, where $T_{0}=$ $T_{s}-T_{a}-T_{b}$. These three steps are presented in Fig. 5.

The dwell time durations $T_{0} \cdot T_{a} \cdot T_{b}$ can be determined by the Volt-Second Principle that can be expressed mathematically as:

$$
\int_{0}^{T_{s}} \vec{V}_{r e f} \cdot d t=\int_{0}^{T_{a}} \vec{V}_{n} \cdot d t+\int_{T_{a}}^{T_{a}+T_{b}} \vec{V}_{n+1} \cdot d t+\int_{T_{a}+T_{b}}^{T_{s}} \vec{V}_{0 / 7} \cdot d t .
$$

Assuming a constant DC-link voltage, we can write equation (8) in sector (1) as: 


$$
\begin{aligned}
& \vec{V}_{r e f} \cdot T_{s}=\vec{V}_{1} \cdot T_{a}+\vec{V}_{2} \cdot T_{b}+\vec{V}_{0 / 7} \cdot T_{0}, \\
& T_{s}=T_{a}+T_{b}+T_{0} .
\end{aligned}
$$

The space vectors in (9) are expressed in polar form:

$$
\vec{V}_{r e f}=V_{r e f} e^{j \theta} \cdot \vec{V}_{1}=\frac{2}{3} V_{d c} \cdot \vec{V}_{2}=\frac{2}{3} V_{d c} e^{j(\pi / 3)} .
$$

Decompose equation (9) into its real and imaginary components:

$$
\begin{cases}\text { Re: } & V_{\text {ref }}(\cos \theta) T_{s}=\frac{2}{3} V_{d c} T_{a}+\frac{1}{3} V_{d c} T_{b}, \\ \operatorname{Im}: & V_{r e f}(\sin \theta) T_{s}=\frac{1}{\sqrt{3}} V_{d c} T_{b} .\end{cases}
$$

Solve two parts of equation (12) together with $T_{s}=T_{a}+T_{b}+T_{0}$ :

$$
\begin{aligned}
& T_{a}=T_{s} m_{a} \sin (\pi / 3-\theta), \\
& T_{b}=T_{s} m_{a} \sin (\theta), \\
& T_{0}=T_{s}-T_{a}-T_{b} .
\end{aligned}
$$

Note that $m_{a}$ is the Modulation Index, and $m_{a}=\frac{\sqrt{3} V_{r e f}}{V_{d c}}$
for SVM. Similar calculations can be made for the duration times for the reference voltage vector in the remaining sectors (2) - (6).

The sequence, in which these dwell times calculated with (13), (14), and (15) are placed, is characteristic; the SVPWM scheme where the effective voltage vectors are placed in the middle of the modulation time interval is called symmetrical SVPWM, and this placement technique shows superior harmonic characteristics.

Table 2: The voltage vectors available in each sector for reference voltage vector formation.

\begin{tabular}{lcccccc}
\hline \hline Angle $\left|\theta_{\text {sector }}\right|$ & $\frac{\pi}{3}$ & $\frac{2 \pi}{3}$ & $\pi$ & $\frac{4 \pi}{3}$ & $\frac{5 \pi}{3}$ & $2 \pi$ \\
\hline Included Vectors & $V_{1} . V_{2}$ & $V_{2} . V_{3}$ & $V_{3} . V_{4}$ & $V_{4} . V_{5}$ & $V_{5 .} . V_{6}$ & $V_{6} . V_{1}$ \\
\hline Sector Number $\left(S_{N}\right)$ & 1 & 2 & 3 & 4 & 5 & 6 \\
\hline \hline
\end{tabular}

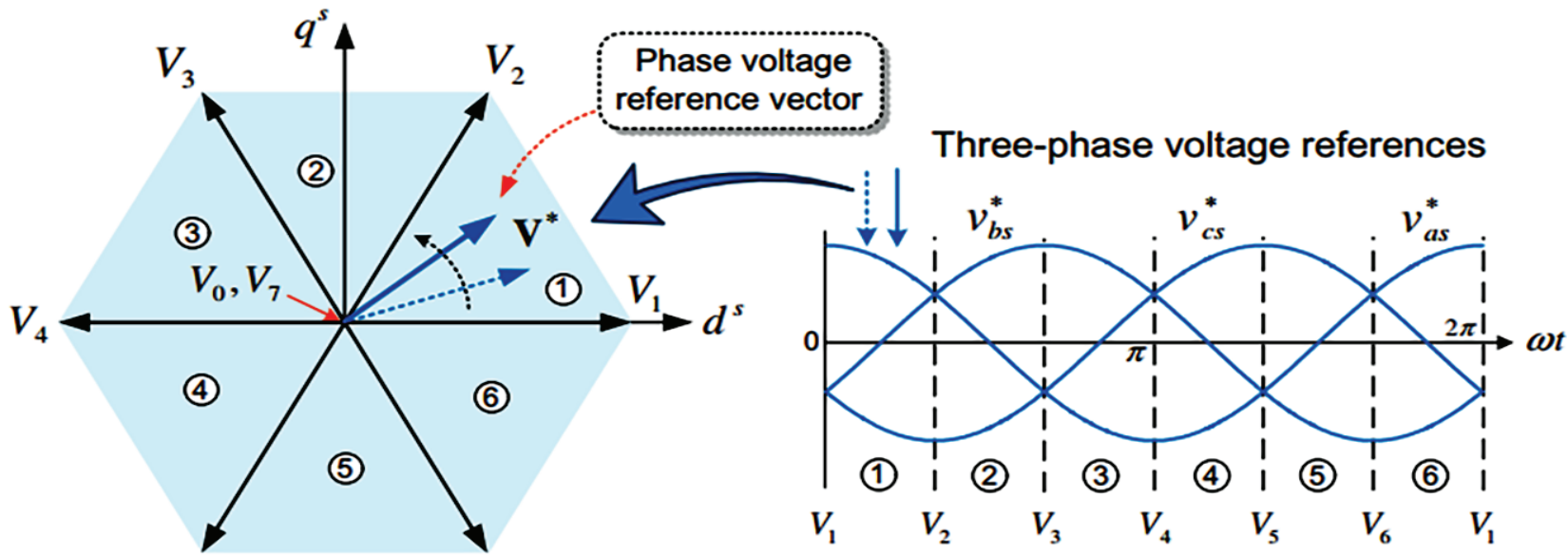

Fig.4. Reference vector rotation in the complex plane [18]

\section{Step 1.}

Apply effective vector 1

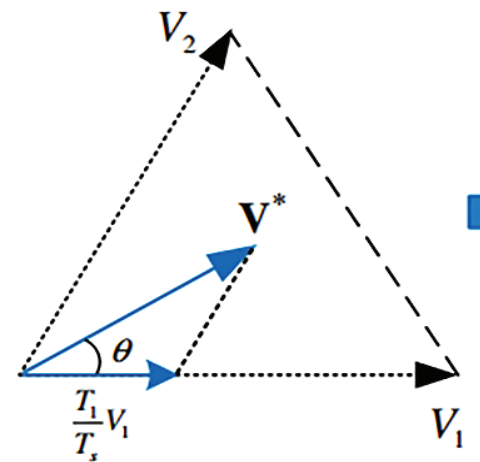

\section{Step 2.}

Apply effective vector 2

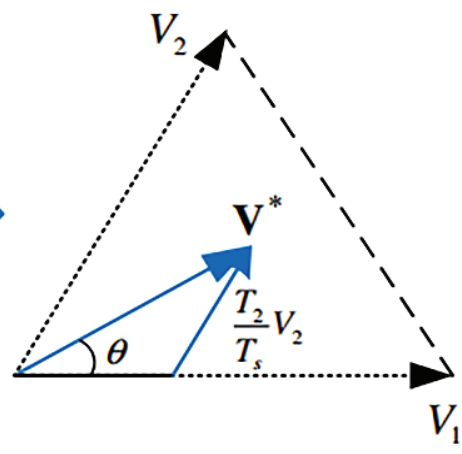

\section{Step 3.}

Apply zero vector

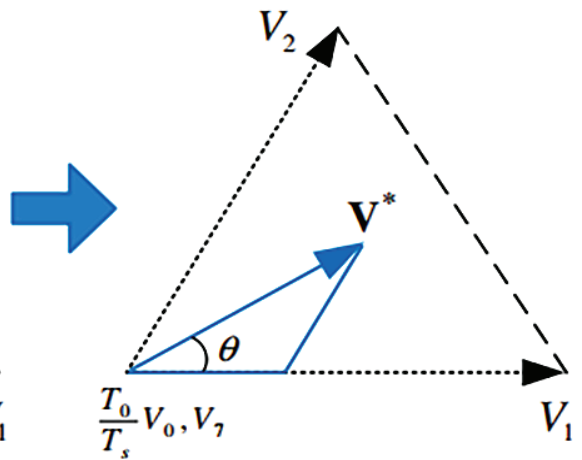

Fig. 5. Reference voltage vector generation process using two inverter-active voltage vectors [18]. 


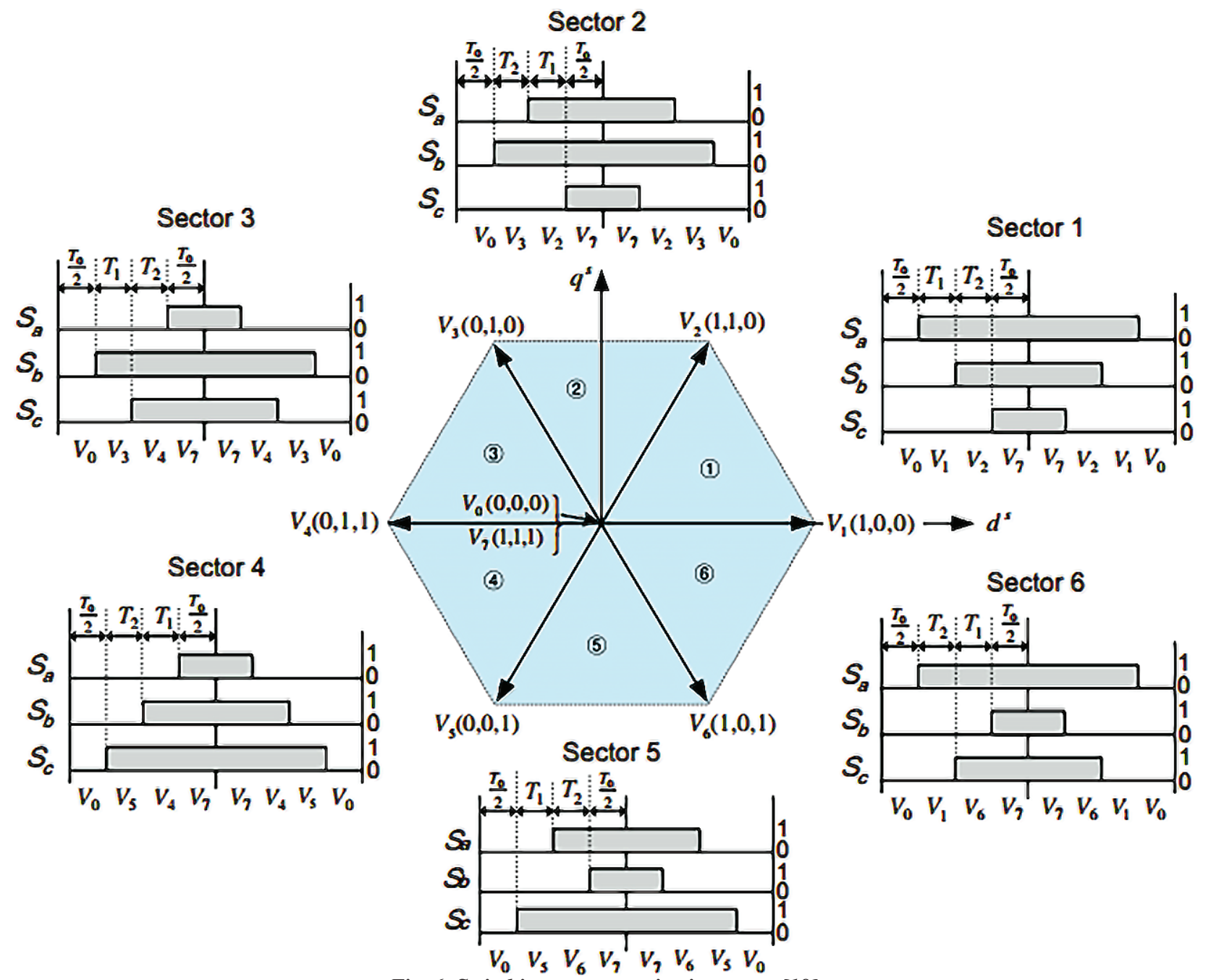

Fig. 6. Switching sequences in six sectors [18].

In this technique, time $T_{0}$ of the two zero vectors $V_{0 / 7}$ is equally divided and distributed at the beginning and end of the modulation time interval $T_{s}$. This will result in a minimum switching frequency since every switch in the inverter is switched only once from an on state to an off state or vice versa in one sampling time interval.

The switching sequences in all six sectors for the symmetrical SVPWM technique are shown in Fig.6. The maximum magnitude of the reference voltage vector $V_{\text {ref. }}$ ${ }_{\max }$ corresponds to the radius of the largest circle inscribed in the hexagon, as explained in [18]. This radius equals $V_{d c} / \sqrt{3}$, which is the maximum fundamental phase voltage achieved with the SVPWM technique. This value is about $15.5 \%$ larger than that of the SPWM technique. Substituting this value in $m_{a}$, we can find the maximum modulation index for SVM as:

$$
m_{a, \max }=\frac{\sqrt{3}\left(V_{d c} / \sqrt{3}\right)}{V_{d c}}=1,
$$

from which the modulation index for the SVM scheme is in the range of

$$
0 \leq m_{a} \leq 1
$$

5. SVPWM technique for three-phase 2L-VSI with a reduced computational burden method

The conventional SVPWM has superior advantages and is preferable in many applications, but it also has its disadvantages. The conventional SVPWM scheme requires a whole host of calculations and a trigonometric computational effort to calculate the switching times of active voltage vectors. Nowadays, however, with the continuous technological advancement and development of more intelligent microprocessors and faster switching devices, nothing remains as it was before, and new techniques and methodologies are proposed, including the one presented in this study.

The presented method can considerably reduce the number of calculations and computational burden and make the concept of SVPWM more simple and more intuitive. The proposed SVPWM method is easily implemented by the carrier-based PWM technique based on the offset voltage procedure [18].

In the two-level sinusoidal PWM inverter, each reference phase voltage is compared with the triangular 


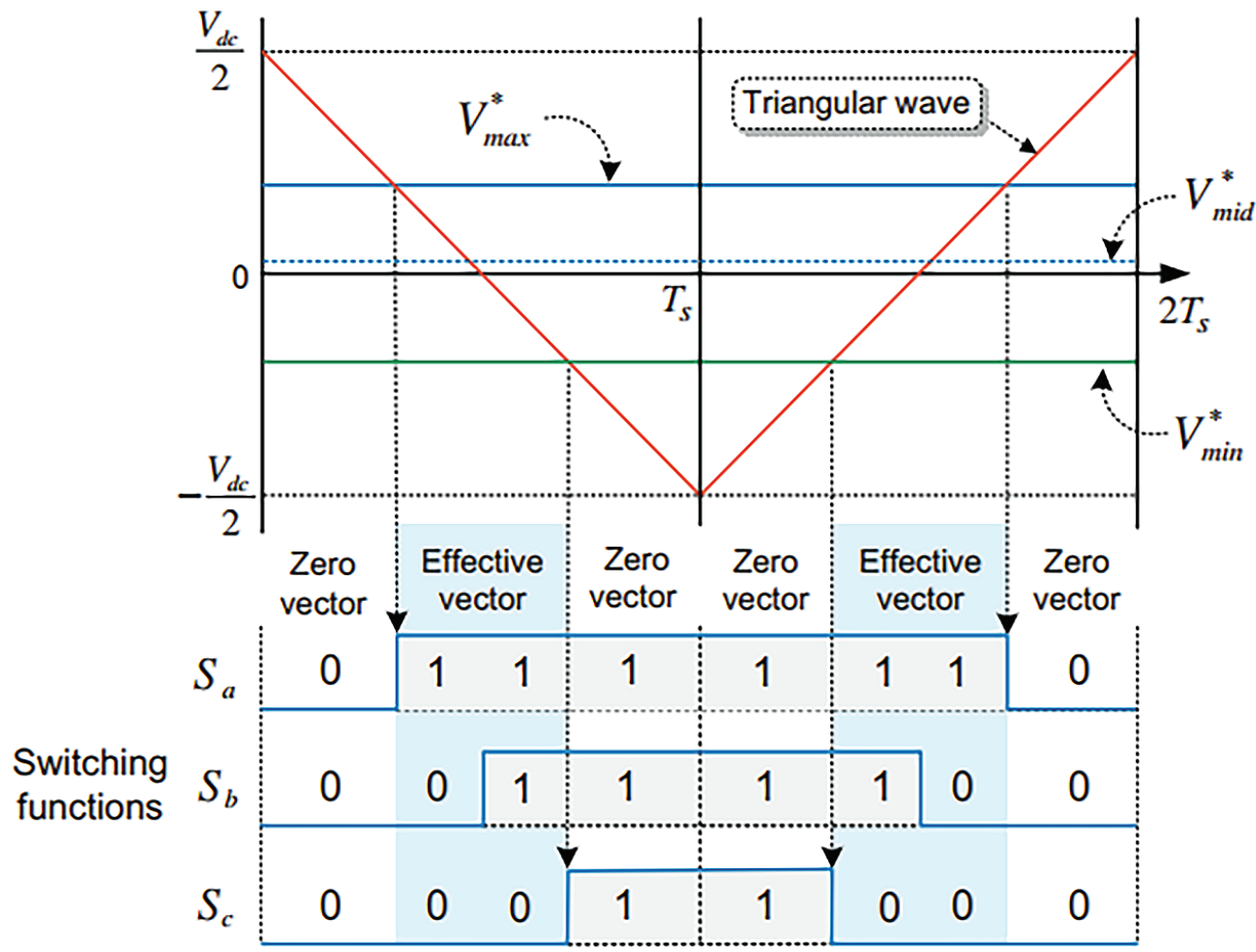

Fig. 7. Centering the effective voltage vectors for symmetrical SVPWM [18].

carrier signal, and separate pole voltages are produced independently of one another. In the presented technique, a common-mode voltage is applied to the reference phase voltages to achieve the maximum possible peak amplitude of the fundamental phase voltage in linear modulation [27], where the magnitude of this common-mode voltage is determined from:

$$
V_{C M}=-\frac{V_{\max }+V_{\min }}{2} .
$$

In equation (17), $V_{\max }$ is the maximum magnitude of the sequenced three-phase voltages, while $V_{\min }$ is the minimum magnitude of the three sequenced reference phase voltages. The introduction of this common-mode voltage in a sampling time interval results in centering the inverter-active vectors in the time interval as presented in Fig.7, making the SVPWM equivalent to the linear SPWM. To determine the reference pole voltages directly from the reference phase voltages, we first need to read the sampled instantaneous reference phase voltages $V_{a s}, V_{b s}, V_{c s}$, and then calculate the time equivalent of these voltages termed as $T_{a s}, T_{b s}$, and $T_{c s}$, respectively.

$$
\begin{aligned}
& T_{a s}=\frac{V_{a s}}{V_{d c}} T_{s}, \\
& T_{b s}=\frac{V_{b s}}{V_{d c}} T_{s}, \\
& T_{c s}=\frac{V_{c s}}{V_{d c}} T_{s} .
\end{aligned}
$$

Sort these times to find $T_{\max }$ and $T_{\min }$, then the time corresponding to the common-mode offset voltage can be found from

$$
T_{\text {offset }}=(1 / 2)\left[T_{s}-\left(T_{\max }+T_{\min }\right)\right]
$$

and the pole voltage times are found from

$$
\begin{aligned}
& T_{g a}=T_{a s}+T_{o f f s e t}, \\
& T_{g b}=T_{b s}+T_{o f f s e t}, \\
& T_{g c}=T_{c s}+T_{\text {offset }},
\end{aligned}
$$

where $V_{d c}$ is the DC-link voltage, $T_{s}$ is the sampling time, and $T_{g a} \cdot T_{g b} \cdot T_{g c}$ are the reference pole voltage-time equivalents. When these time signals are compared with the carrier-based triangular wave, the outputs are the gating signals for the upper switches in each inverter leg to be turned on. With the procedure of the aforementioned equations (18)-(22), the reference pole voltages are directly determined from the reference phase voltages without any heavy calculations or computational effort mentioned. A schematic diagram for this operation is introduced in Fig.8.

Since the offset voltage can be freely determined within specific limitations, in this way, many PWM techniques can be directly incorporated by using a convenient offset voltage depending on the reshaped pole voltage reference, and this alteration leads to a shift in the zero-vector time distribution. Thus, without any change in its duty cycle, the position of the effective voltage can be relocated in the sampling interval, as the three-pole voltage references are changed with the offset voltage. 


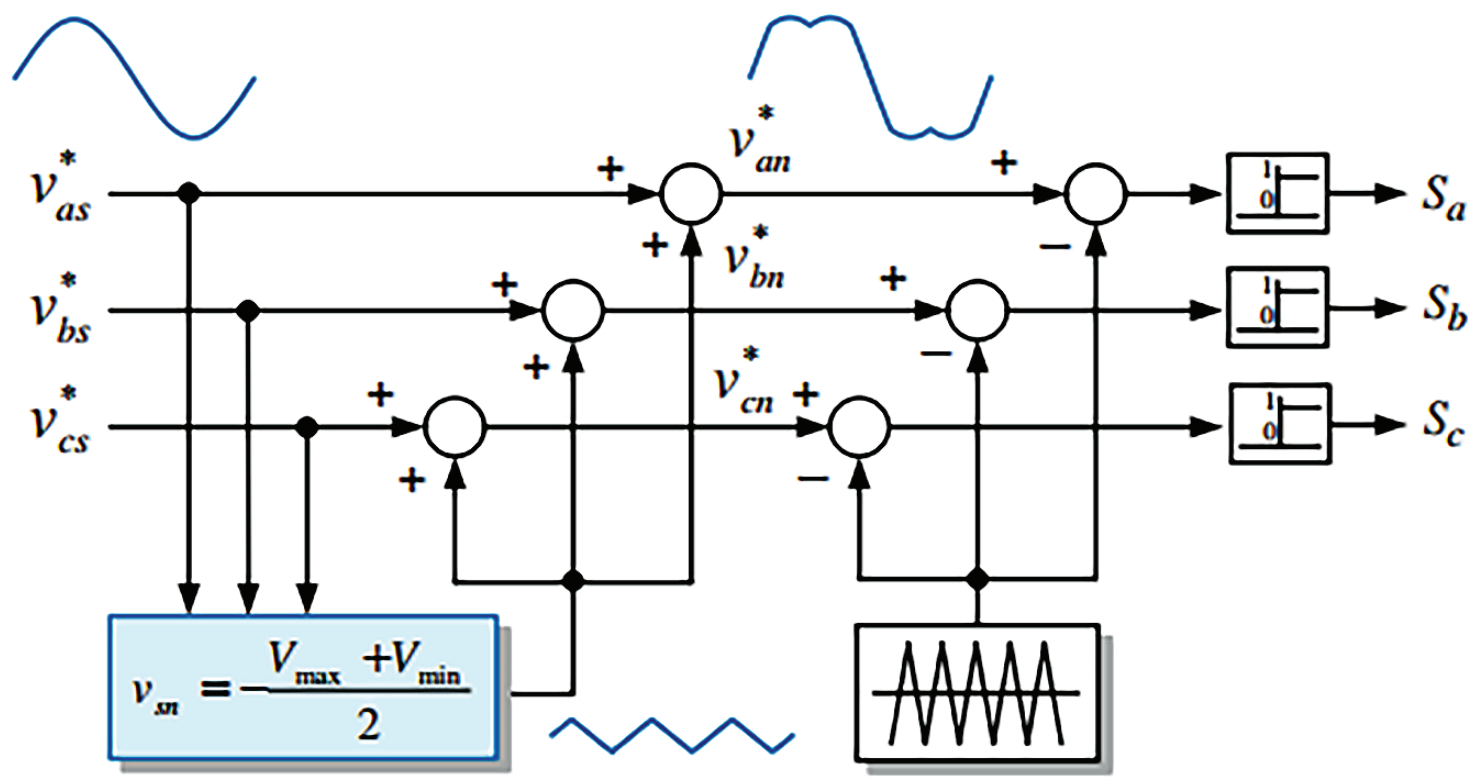

Fig.8. Equivalent SVPWM technique using the offset voltage [18].

\section{The overall control procedure}

The proposed simplified SVPWM for the three-phase 2L-VSC -fed RL load can be summarized as follows:

Step 1: Sample the three-phase sinusoidal reference voltages, determine the associated time equivalents by equations (18) to (20).

Step 2: Sort these times to find $T_{\max }$ and $T_{\min }$.

Step 3: Calculate the offset voltage-time equivalent $T_{\text {offset }}$ using (21).

Step 4: Add the time offset calculated in step 3 and the equivalent time references to find the pole voltage times from (22).

Step 5: Compare the waveforms that result from step 4 with the triangular carrier signal to find switching pulses of the upper switch in each inverter leg.

\section{SIMULATION RESULTS AND DISCUSSION}

To assess the performance of the proposed simplified SVPWM method based on the offset voltage, the output characteristics were compared with the conventional SVPWM and the SPWM procedures using MATLAB/ SIMULINK software. The simulation results and expected performance of the three techniques, including SPWM, conventional SVPWM, and the proposed reduced SVPWM with an offset signal, are shown ordered in each Figure with (a), (b), and (c), respectively.

The simulation conditions are constant DC-link voltage $V_{d c}=400 \mathrm{~V}$, modulating signal frequency $f_{m}=50$ $\mathrm{Hz}$, frequency modulation index $m_{f}=9,15$, and variable amplitude modulation index $m_{a}=0.1,0.9$, and 1.15 , with the inverter output connected to an RL load with $R=10$ $\Omega, L=100 \mathrm{mH}$. Simulation is performed for $f_{c r}=450$ $\mathrm{Hz}$ and $750 \mathrm{~Hz}$ corresponding to $m_{f}=9,15$ to achieve synchronization and waveform symmetry [28]. The system steady-state is investigated with the three algorithms. The results for modulation indexes $0.1,0.9$, and 1.15 are presented in Fig. 9, Fig. 10, and Fig. 11 for $m_{f}=9$, and in Fig. 12, Fig. 13, and Fig. 14 for $m_{f}=15$, respectively. The sampling time for all three algorithms is $T_{s}=\left(1 / f_{c r}\right) \mathrm{s}$, given that $f_{c r}=m_{f} \times f_{m}$.

It is worth mentioning that the execution time for the proposed method is shorter than that of the conventional SVM since the number of sector-time calculations is reduced considerably in the former. Close inspection shows that the output voltage produced by the presented technique is closer to the result from the SPWM than that of the conventional SVPWM, although its harmonic content is less than that of SPWM but higher than that of the conventional SVPWM. The fast Fourier transform (FFT) analysis of the inverter line voltage with the three techniques is shown in Fig. 15.

The data shown in the Figure indicate that the conventional SVM has the fundamental output voltage of $363.7 \mathrm{~V}$, which is 0.167 times more than that of the SPWM (311.6 V), while the fundamental output voltage of the simplified SVM $(357 \mathrm{~V})$ is 0.144 times greater than the fundamental line voltage of the SPWM. The THD values are $79.28 \%, 62.27 \%$, and $65.38 \%$ for the three methods (SPWM, conventional SVPWM, and simplified SVPWM), respectively. Such results assure that the technique proposed can be implemented instead of the conventional SVM control method with the benefit of getting a shorter execution time and similar performance parameters like peak output voltage and THD value. Shorter execution time opens the way for a lower-cost microprocessor to be used for implementing such a control circuit, in addition to fast response and lower memory usage characteristics, which will be achieved with the simplified SVM control method. 

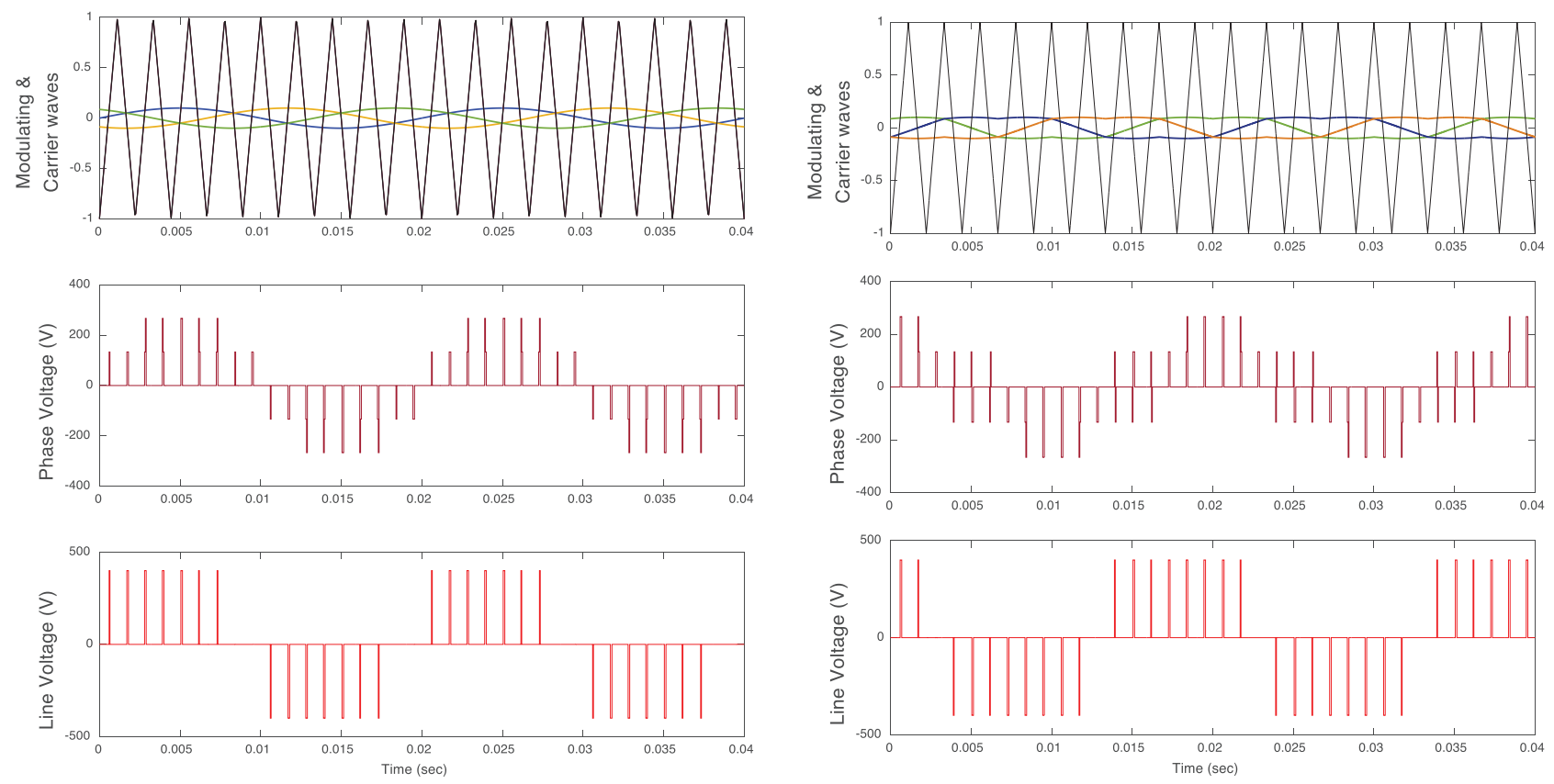

(a)

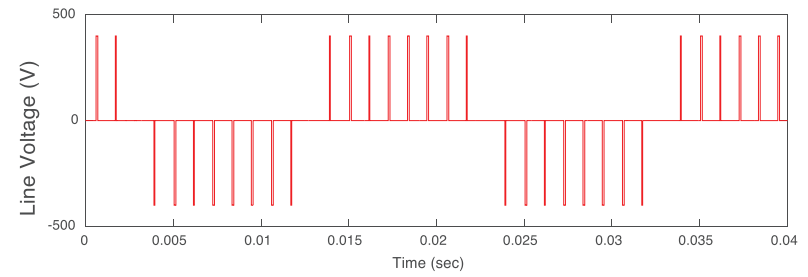

(b)
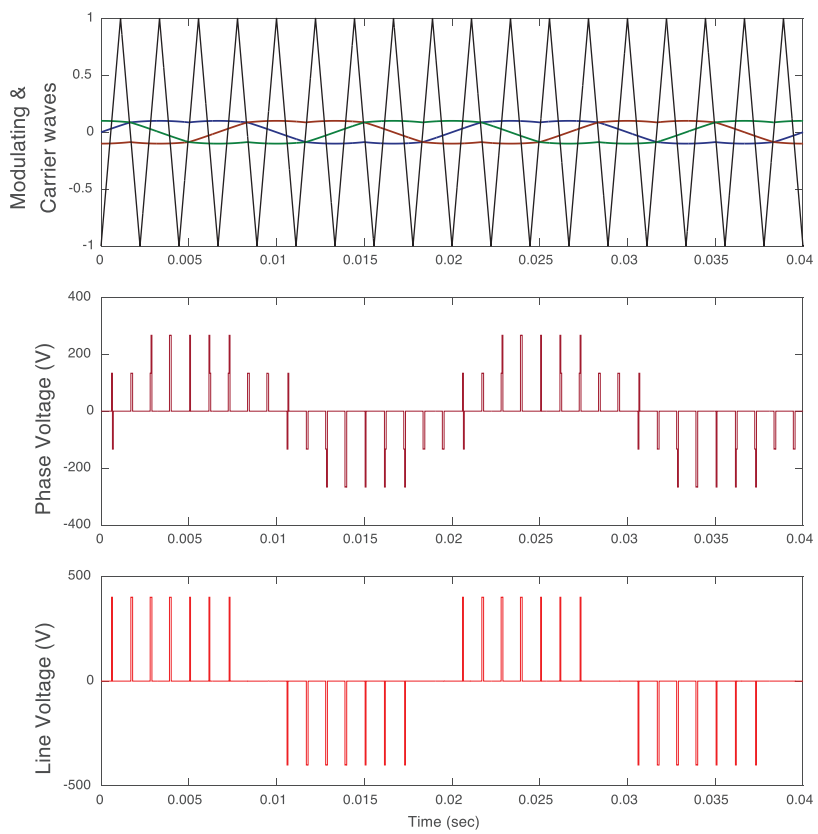

(c)

Fig. 9. Simulation results with $m a=0.1$ and $m f=9$ ( $f s w=450 \mathrm{~Hz}$ ) for (a) SPWM, (b) conventional SVPWM, and (c) SVPWM with offset signal. 

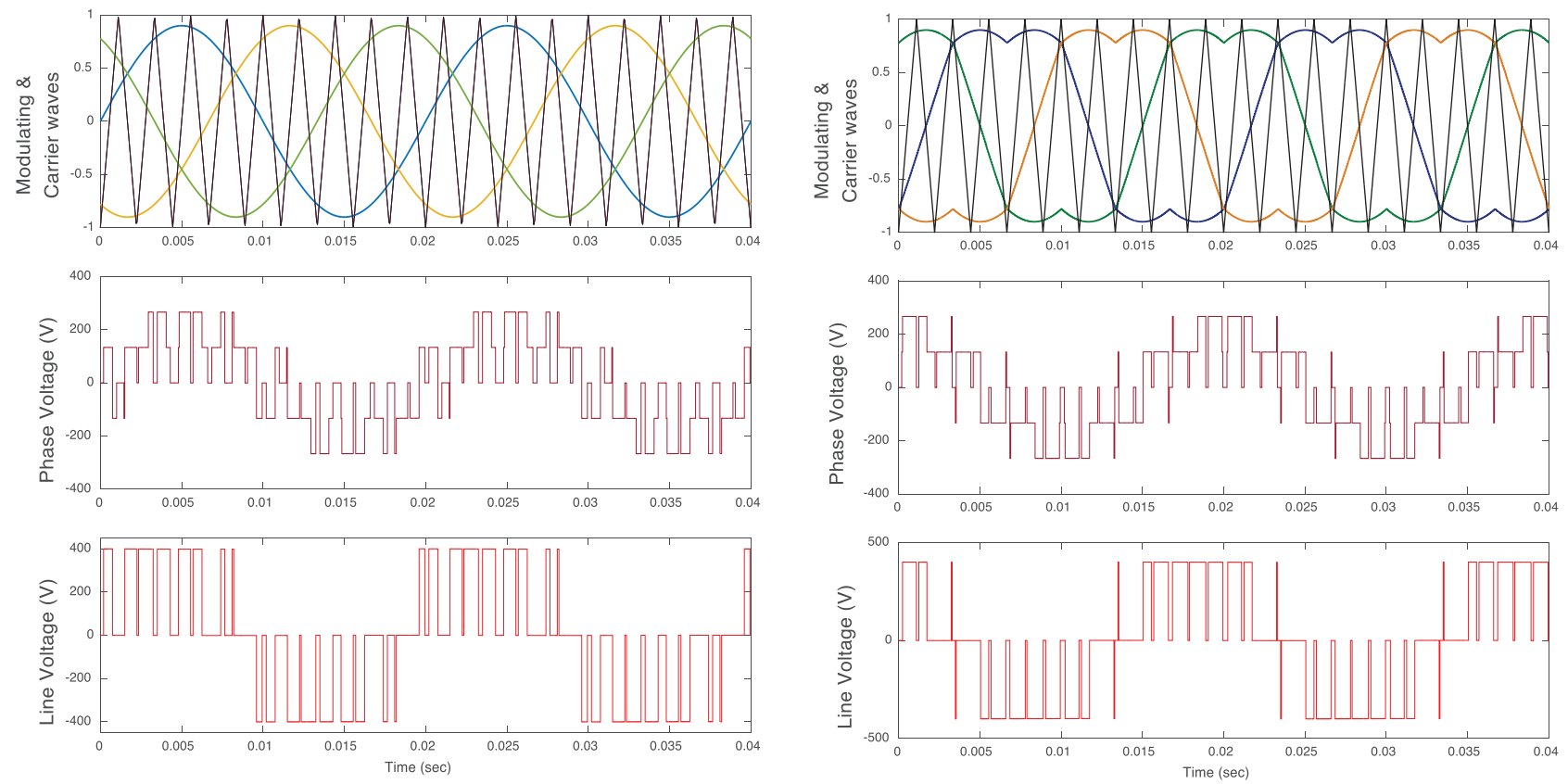

(a)

(b)
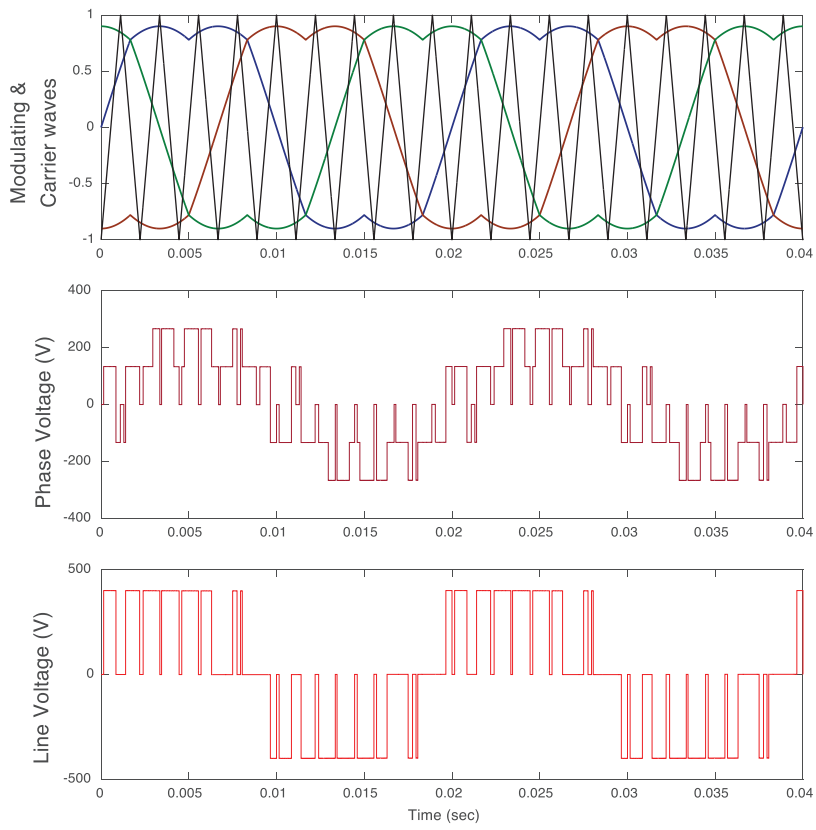

(c)

Fig. 10. Simulation results with $m a=0.9$ and $m f=9$ ( $f s w=450 \mathrm{~Hz}$ ) for (a) $S P W M$, (b) conventional $S V P W M$, and (c) SVPWM with offset signal. 

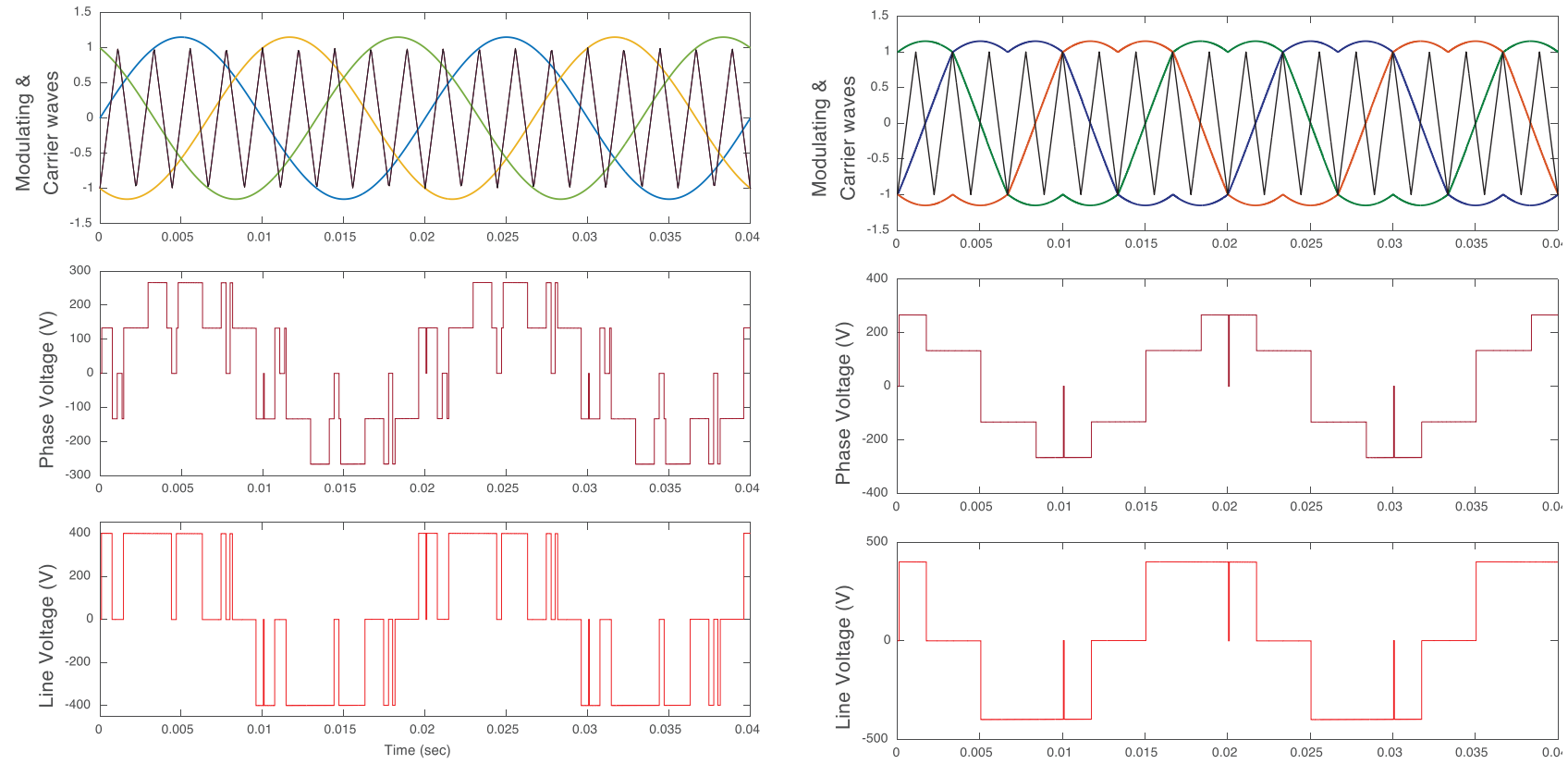

(a)

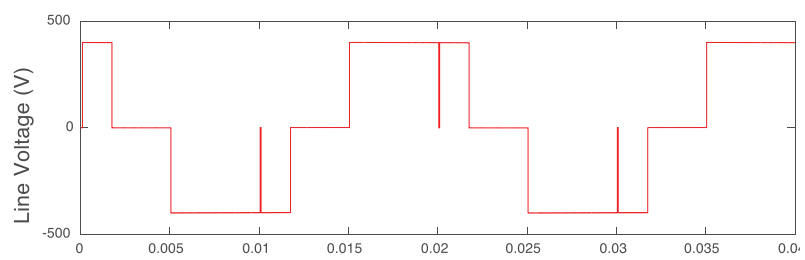

(b)
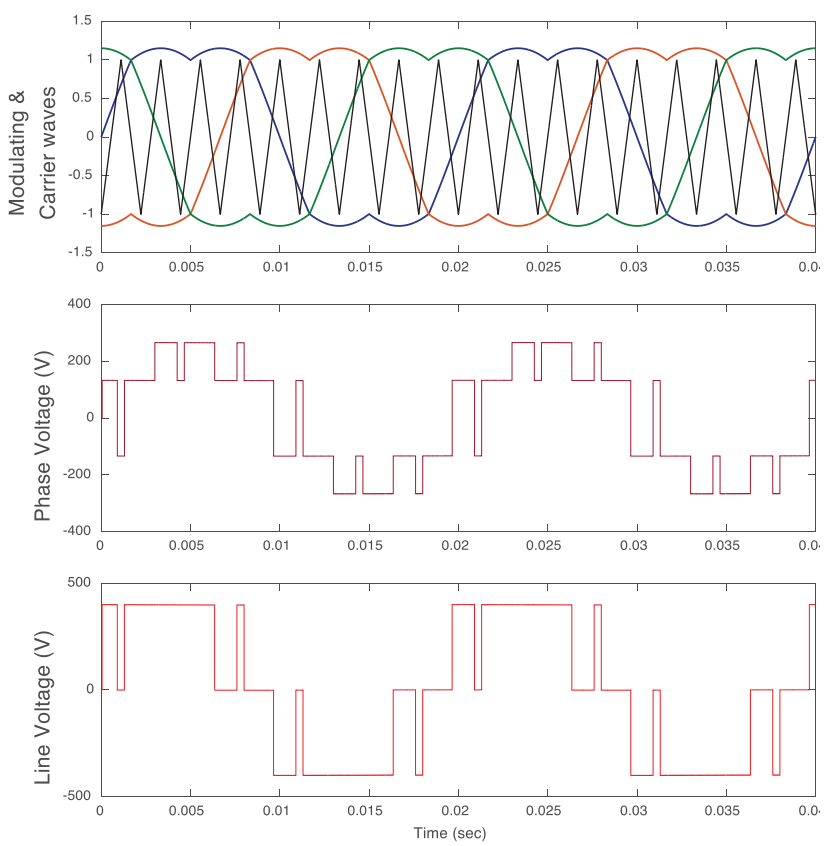

(c)

Fig. 11. Simulation results with $m a=1.15$ and $m f=9(f s w=450 \mathrm{~Hz})$ for (a) $S P W M$, (b) conventional $S V P W M$, and (c) SVPWM with offset signal. 

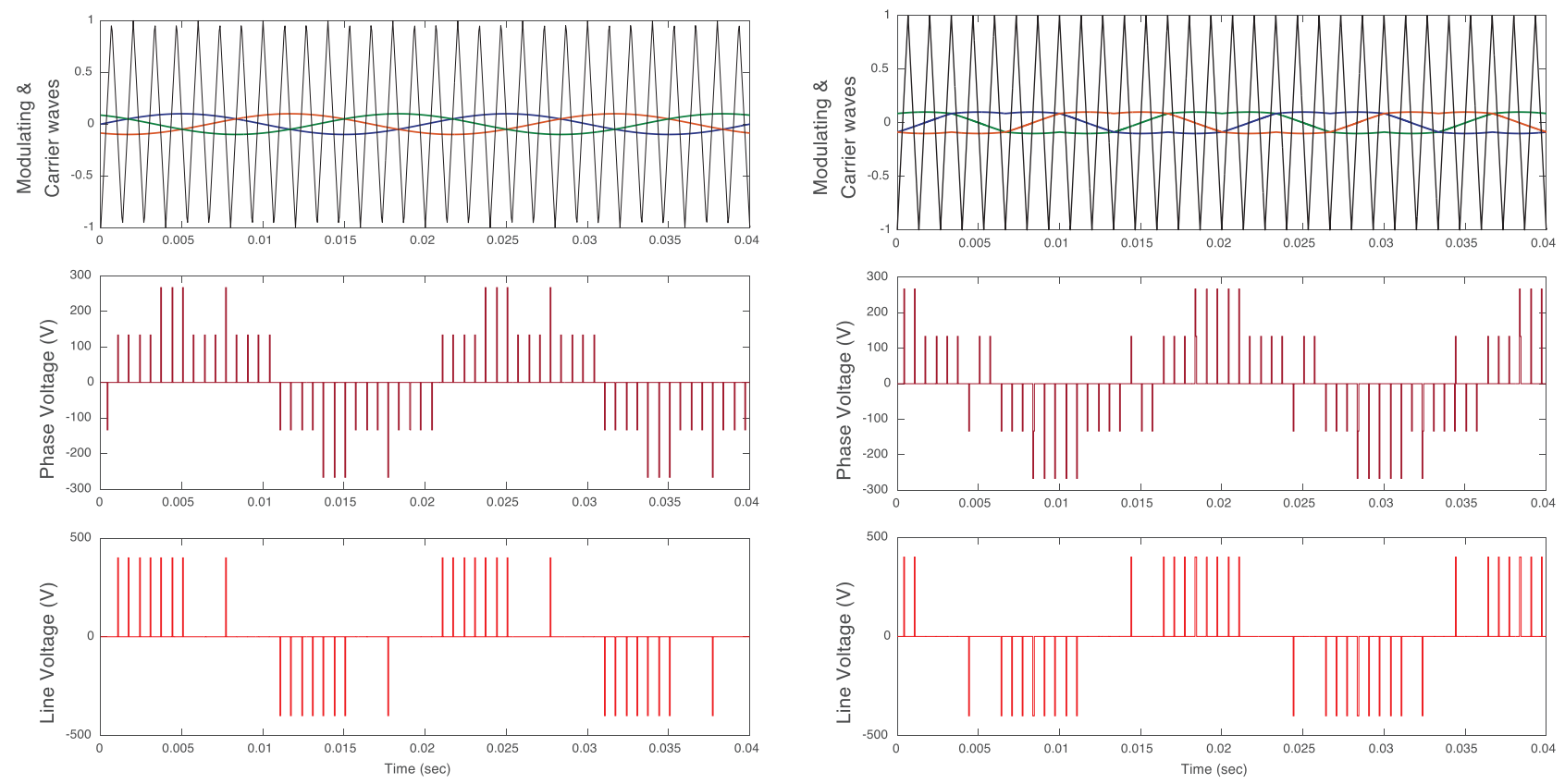

(a)

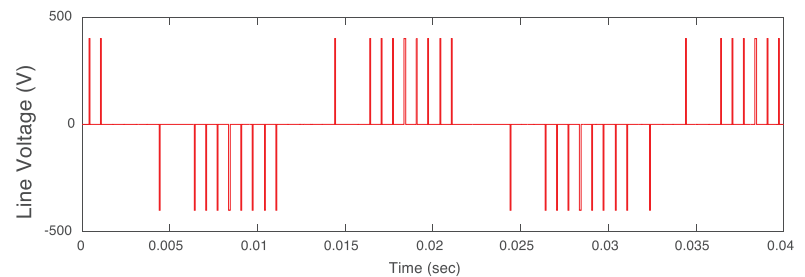

(b)
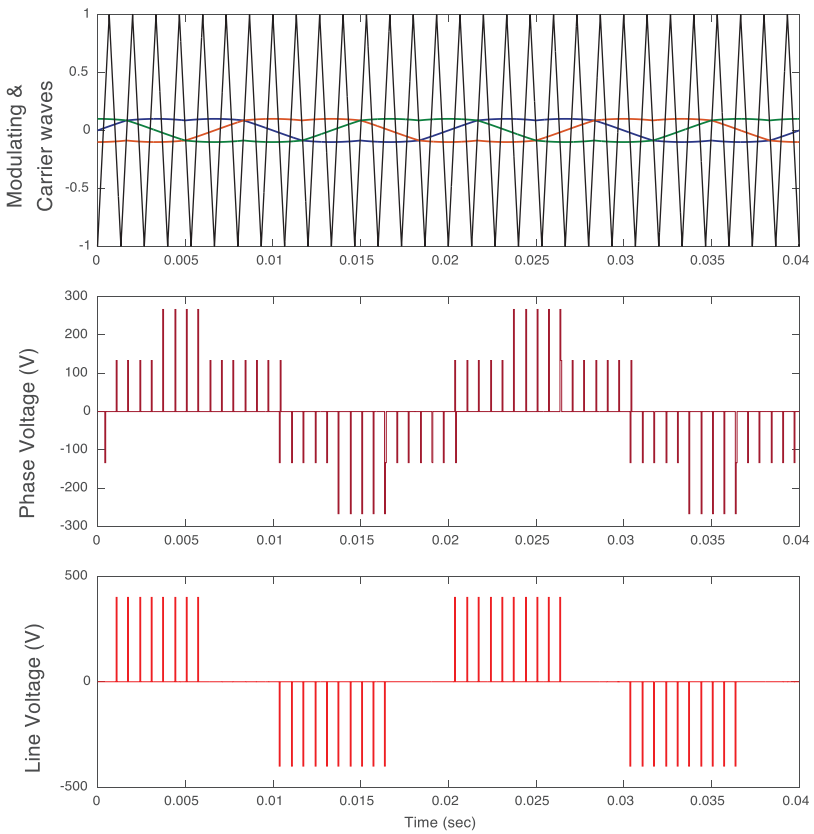

(c)

Fig. 12. Simulation results with $m a=0.1$ and $m f=15$ ( $f s w=750 \mathrm{~Hz}$ ) for (a) $S P W M$, (b) conventional $S V P W M$, and (c) $S V P W M$ with offset signal. 

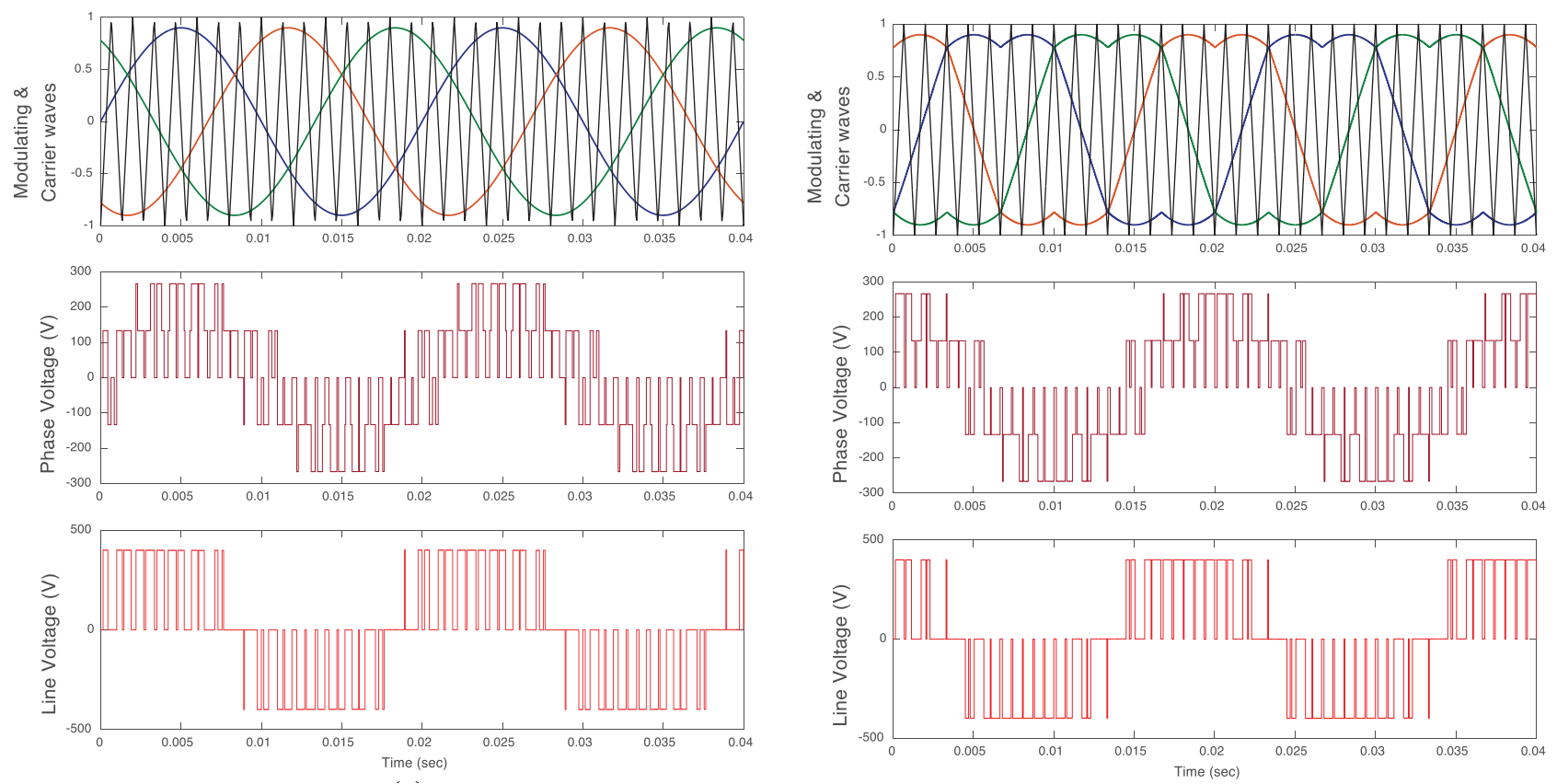

(a)

(b)
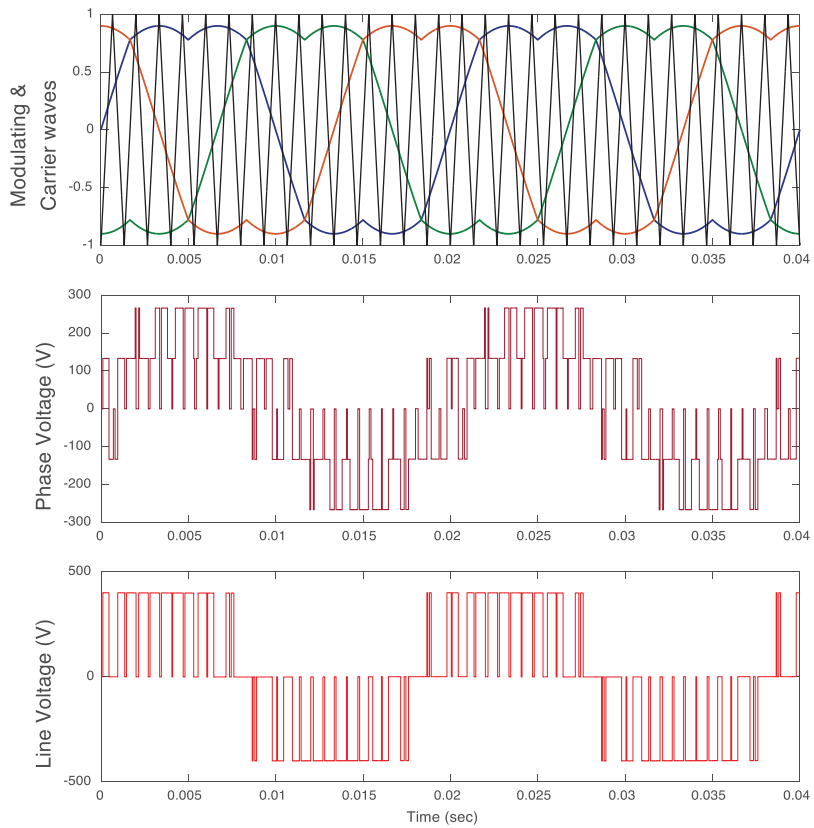

(c)

Fig. 13. Simulation results with $m a=0.9$ and $m f=15$ ( $f s w=750 \mathrm{~Hz}$ ) for (a) $S P W M$, (b) conventional $S V P W M$, and (c) $S V P W M$ with offset signal. 

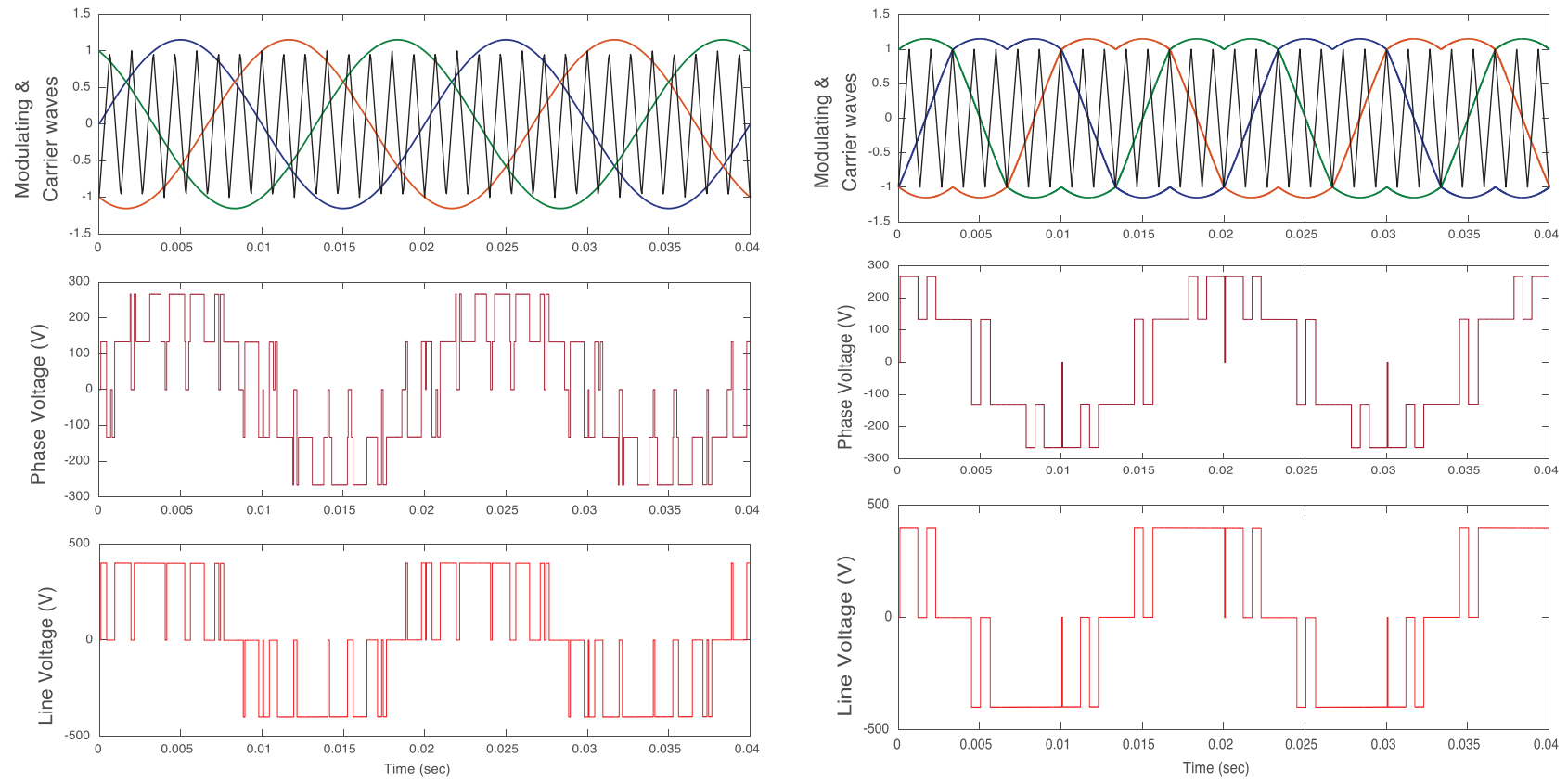

(a)

(b)
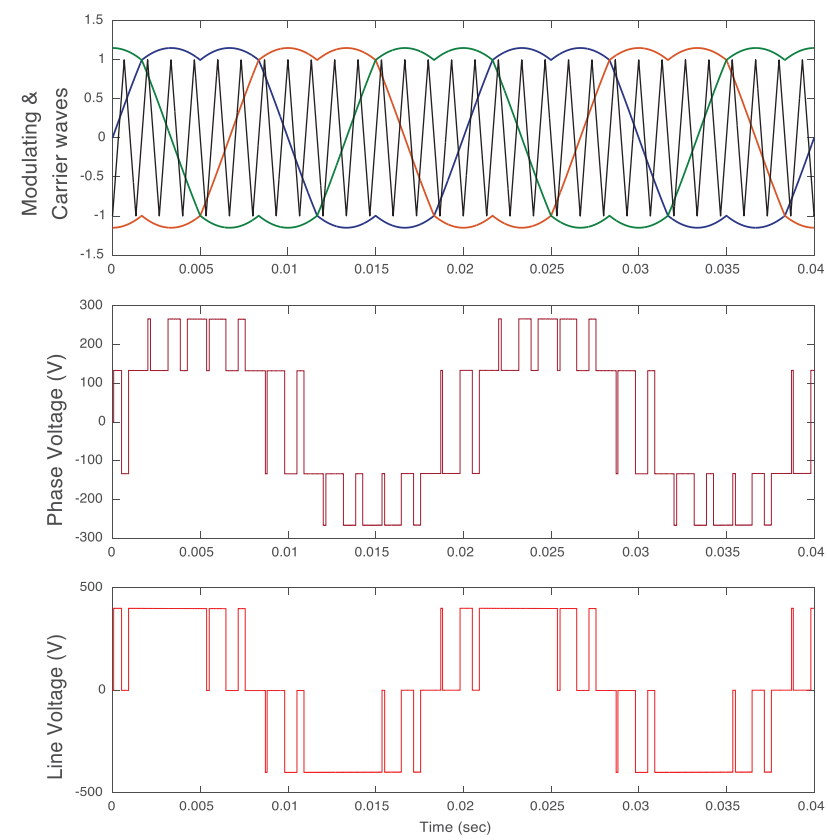

(c)

Fig. 14. Simulation results with $m a=1.15$ and $m f=15$ (fsw $=750 \mathrm{~Hz}$ ) for (a) SPWM, (b) conventional SVPWM, and (c) SVPWM with offset signal. 


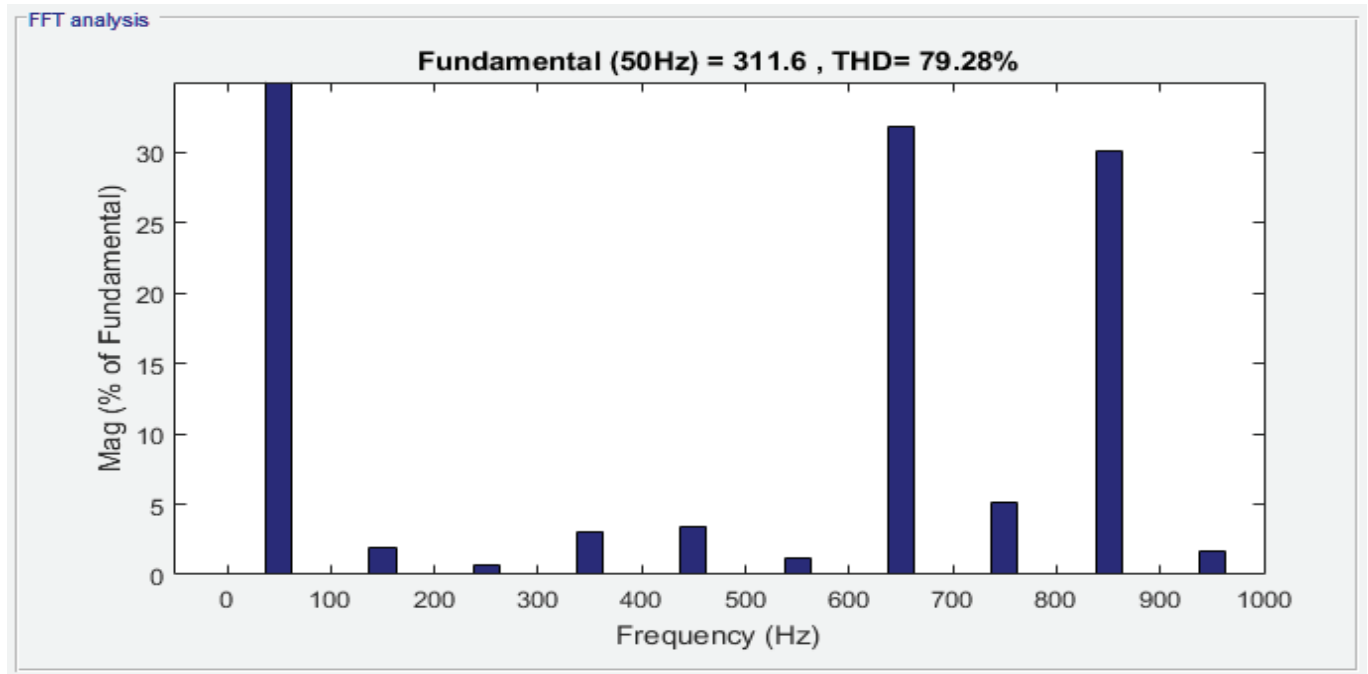

(a)

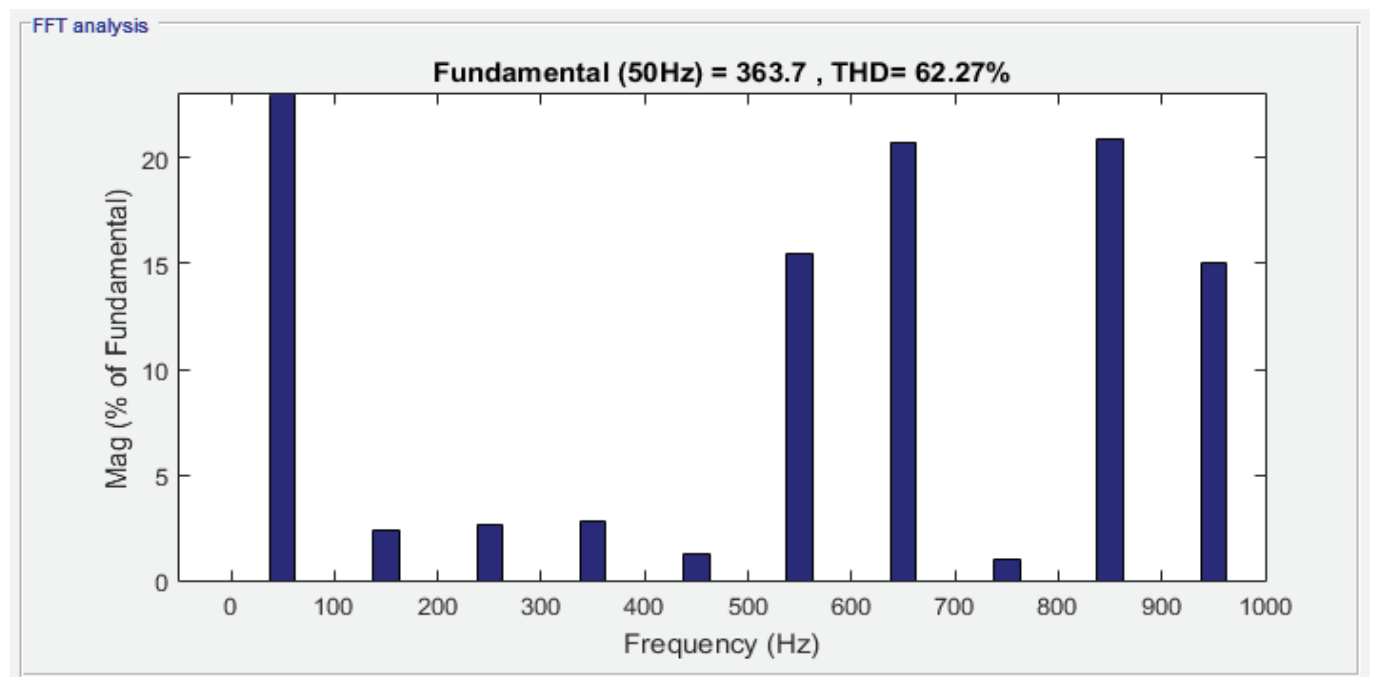

(b)

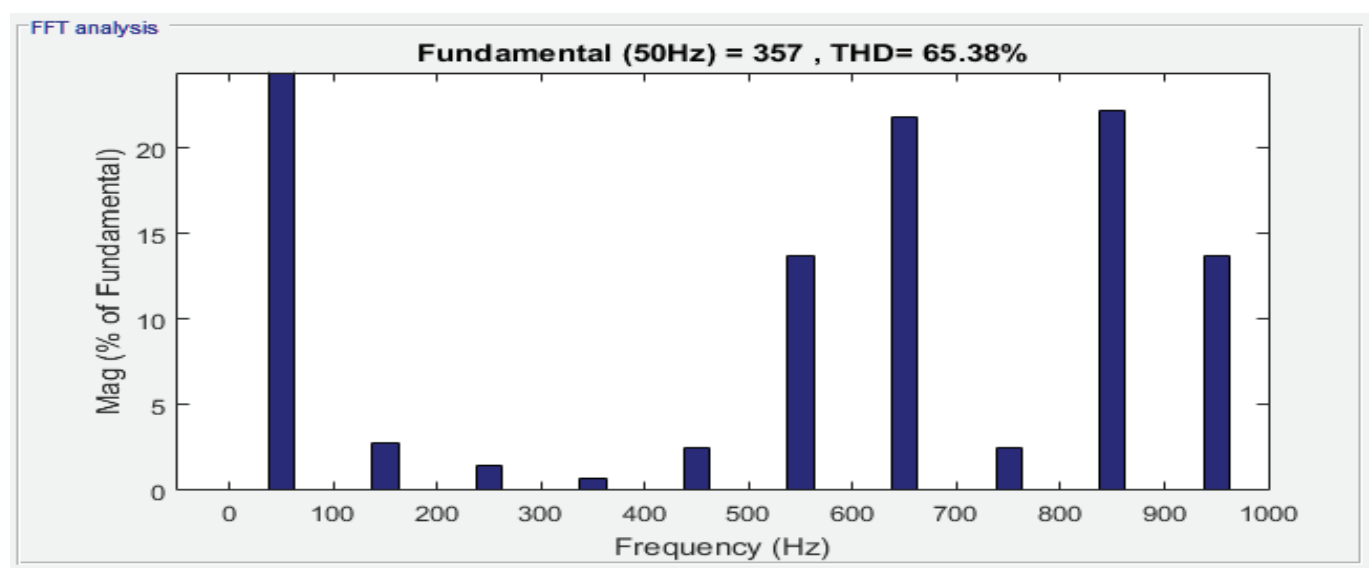

(c)

Fig. 15. FFT analysis of the output line voltage expressed as a \% of fundamental line voltage with $m a=0.9$ and $m f=15(f s w=750 \mathrm{~Hz}$ ) for (a) $S P W M$, (b) conventional $S V P W M$, and (c) SVPWM with offset signal. 


\section{CONCLUSION}

Several PWM techniques can be used to control three-phase Voltage Source Converters for industrial and variable frequency AC drive applications. This paper proposes a software preprogrammed code for SVPWM implementation with a reduced computational time strategy. The simplified SVPWM method relies on the offset voltage principle and factors in the symmetry and synchronization achieved between the output voltage and its fundamental component to remove any possible subharmonics. SVM utilizes the DC voltage more efficiently than the SPWM since its output voltage is about $15.5 \%$ greater than that of SPWM. Conventional SVM is a superior modulation technique but its enormous number of calculations needed to determine the switches gating signals struggles and diminishes its application in relatively small real-time implementations. The proposed simplified SVM method avoids the conventional time-sector calculations and reproduces approximately the same modulating signal as the conventional way, directly from the sampled sinusoidal three-phase reference voltages without any appreciably mentioned calculations.

The simulation results indicate that the performance achieved is very similar to that of the conventional SVM but with a decreased algorithm execution time, which allows using lower-cost microcontrollers for the same components and circuit utilization. The proposed method waveforms have an appearance similar to that of the SPWM and performance parameters roughly like the original SVPWM.

\section{REFERENCES}

[1] S. Toledo, M. Rivera, and J. L. Elizondo, “Overview of wind energy conversion systems development, technologies and power electronics research trends," 2016 IEEE Int. Conf. Autom. ICA-ACCA 2016, 2016, DOI: 10.1109/ICA-ACCA.2016.7778454.

[2] F. Blaabjerg, T. Dragicevic, and P. Davari, "Applications of power electronics," Electron., vol. 8, no. 4, 2019, DOI: $10.3390 /$ electronics8040465.

[3] M. M. Mahmoud, M. M. Aly, and A.-M. M. AbdelRahim, "Enhancing the dynamic performance of a wind-driven PMSG implementing different optimization techniques," SN Appl. Sci., 2020, DOI: 10.1007/s42452-020-2439-3.

[4] J. Sabarad and G. H. Kulkarni, "Comparative analysis of SVPWM and SPWM techniques for multilevel inverter,” 2015, DOI: 10.1109/ICPACE.2015.7274949.

[5] T. Brückner and D. G. Holmes, "Optimal pulse-width modulation for three-level inverters," IEEE Trans. Power Electron., vol. 20, no. 1, pp. 82-89, 2005, DOI: 10.1109/TPEL.2004.839831.

[6] S. Vazquez, J. Rodriguez, M. Rivera, L. G. Franquelo, and M. Norambuena, "Model Predictive Control for Power Converters and Drives: Advances and Trends," IEEE Trans. Ind. Electron., 2017, DOI: 10.1109/ TIE.2016.2625238.
[7] P. Falkowski and A. Sikorski, "Comparative Analysis of Finite Control Set Model Predictive Control Methods for Grid-Connected AC-DC Converters with LCL Filter," IEEE Int. Symp. Ind. Electron., vol. 2018-June, pp. 193-200, 2018, DOI: 10.1109/ISIE.2018.8433673.

[8] B. Chokkalingham, S. Padmanaban, and F. Blaabjerg, "Investigation and Comparative Analysis of Advanced PWM Techniques for Three-Phase Three-Level NPC-MLI Drives," Electr. Power Components Syst., vol. 46, no. 3, pp. 258-269, 2018, DOI: 10.1080/15325008.2018.1445142.

[9] M. M. Mahmoud, M. M. Aly, H. S. Salama, and A. M. M. Abdel-Rahim, «Dynamic evaluation of optimization techniques-based proportional-integral controller for wind-driven permanent magnet synchronous generator,» Wind Eng., 2020, DOI: 10.1177/0309524X20930421.

[10] N. Prakash, J. Jacob, and V. Reshmi, "Comparison of DVR performance with Sinusoidal and Space Vector PWM techniques," 2014 Annu. Int. Conf. Emerg. Res. Areas Magn. Mach. Drives, AICERA/iCMMD 2014 Proc., 2014, DOI: 10.1109/AICERA.2014.6908196.

[11] C. Hari Krishna, J. Amarnath, and S. Kamakshaiah, "Simplified SVPWM algorithm for neutral point clamped 3-level inverter fed DTC-IM drive," 2012 Int. Conf. Adv. Power Convers. Energy Technol. APCET 2012, 2012, DOI: 10.1109/APCET.2012.6302002.

[12] R. V. Thomas, E. Rakesh, J. Jacob, and A. Chitra, "Identification of optimal SVPWM technique for diode clamped multilevel inverter based induction motor drive," Proc. 2015 IEEE Int. Conf. Electr. Comput. Commun. Technol. ICECCT 2015, 2015, DOI: 10.1109/ ICECCT.2015.7225926.

[13] A. R. Beig, M. Poshtan, and S. Kanukollu, "Novel SVPWM based switching sequences for modular multilevel DC to AC converter," Conf. Proc. - IEEE Appl. Power Electron. Conf. Expo. - APEC, vol. 2019-March, pp. 1858-1864, 2019, DOI: 10.1109/ APEC.2019.8721773.

[14] M. M. Mahmoud, A. Mohamed Hemeida, and A. M. M. Abdel-Rahim, "Behavior of PMSG Wind Turbines with Active Crowbar Protection under Faults," 2019, DOI: 10.1109/i-PACT44901.2019.8960004.

[15] K. V. Kumar, P. A. Michael, J. P. John, and S. S. Kumar, "Simulation and Comparison of Spwm and Svpwm Control for Three Phase Inverter," ARPN J. Eng. Appl. Sci., 2010.

[16] A. R. Beig, G. Narayanan, and V. T. Ranganathan, «Modified SVPWM algorithm for three-level VSI with synchronized and symmetrical waveforms,» IEEE Trans. Ind. Electron., vol. 54, no. 1, pp. 486-494, 2007, DOI: 10.1109/TIE.2006.888801.

[17] J. S. Lee, K. B. Lee, and F. Blaabjerg, "Predictive Control with Discrete Space-Vector Modulation of Vienna Rectifier for Driving PMSG of Wind Turbine Systems," IEEE Trans. Power Electron., vol. 34, no. 12, pp. 12368-12383, 2019, DOI: 10.1109/ TPEL.2019.2905843. 
[18] S. H. Kim, Electric Motor Control: DC, AC, and BLDC Motors, 1st edition. Elsevier Science, 2017.

[19] G. Chen, A. Bahrami, S. Member, M. Narimani, and S. Member, "A New Seven-Level Topology for HighPower Medium-Voltage Application," vol. 0046, no. c, 2019, DOI: 10.1109/TIE.2019.2962456.

[20] M. M. Mahmoud, A. M. Hemeida, T. Senjy, and A. M. Ewais, "Fault Ride-Through Capability Enhancement For Grid-Connected Permanent Magnet Synchronous Generator Driven by Wind Turbines," in 2019 IEEE Conference on Power Electronics and Renewable Energy (CPERE), 2019, pp. 567-572.

[21] M. Metwally Mahmoud, H. S. Salama, M. M. Aly, and A. M. M. Abdel-Rahim, "Design and implementation of FLC system for fault ride-through capability enhancement in PMSG-wind systems," Wind Eng., 2020, DOI: 10.1177/0309524X20981773.

[22] D. R. Trainer, C. C. Davidson, C. D. M. Oates, N. M. Macleod, and D. R. Critchley, «CIGRE 2010 A New Hybrid Voltage-Sourced Converter for HVDC Power Transmission AREVA T \& D HVDC \& FACTS Stafford, UK R . W . CROOKES AREVA T \& D Technology Centre,» Converter, 2010.

[23] V. K. Singh, R. N. Tripathi, and T. Hanamoto, "HIL cosimulation of finite set-model predictive control using FPGA for a three-phase VSI system," Energies, 2018, DOI: 10.3390/en11040909.

[24] "Pulse-width modulation - WikiMili, The Free Encyclopedia."

[25] D. G. Holmes and T. A. Lipo, "Pulse Width Modulation for Power Converters," Pulse Width Modul. Power Convert., 2010, DOI: 10.1109/9780470546284.

[26] M. H. Rashid, Power Electronics Handbook, 4th ed. Elsevier Inc, 2018.

[27] M. Gaballah, M. El-Bardini, S. Sharaf, and M. Mabrouk, "Implementation of Space Vector-PWM for Driving Two Level Voltage Source Inverters," J. Eng. Sci., vol. 39, no. 4, pp. 871-884, 2011.

[28] Q. Ge, X. Wang, S. Zhang, L. I. Yaohua, and L. Kong, "A high power NPC three-level inverter equipped with IGCTs," 2004

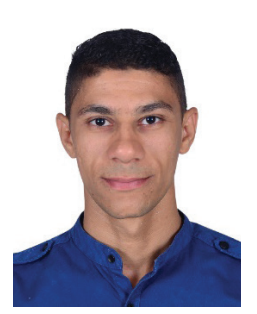

Mohamed Khalid Ratib was born in Sohag, Egypt, in 1993. He received his B.Sc. and M.Sc. degrees in Electrical Engineering from Aswan University, Aswan, Egypt, in 2016 and 2020, respectively. Since, 2017 he has been with the Department of Electrical Engineering, Aswan University, as a Teaching Assistant. His research interests include wind generators, solidstate transformers, power converters, MPC techniques, PWM techniques, and renewable energy conversion systems.

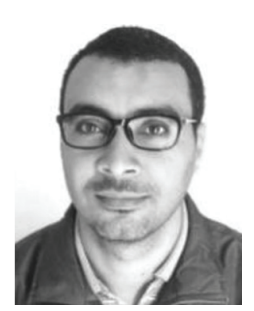

Ahmed Rashwan was born in Sohag, Egypt, in 1984. He received his B.Sc. and M.Sc. degrees from Aswan University, Aswan, Egypt, in 2006 and 2012, respectively. In 2007, he joined the Department of Electrical Engineering, Faculty of Energy Engineering, Aswan University, Aswan, Egypt, as an Administrator, and became a Research Assistant in 2008. In 20152016, he joined the Power Energy System Control Laboratory, University of the Ryukyus, Japan, as a Researcher. His research interests include predictive control modulation of power converters in addition to renewable energy applications. 